\title{
MARS ROVER RTG STUDY
}

\section{Principal Investigator \& Author:}
A. Schock

\section{July 7,1989}

Contributors:

T. Hamrick

T. Or

V. Sankarankandath

M. Shirbacheh

E. Skrabek

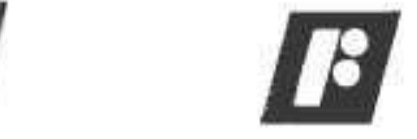





\title{
MARS ROVER RTG STUDY
}

\author{
July 7, 1989
}

Principal Investigator \& Author:

A. Schock
Contributors:

T. Hamrick

T. Or

V. Sankarankandath

M. Shirbacheh

E. Skrabek 


\section{MARS ROVER RTG DESIGN STUDY}

\section{$\underline{\text { Preface }}$}

This volume contains preprints of three papers to be presented at the 1988 Intersociety Energy Conversion Engineering Conference. These are the result of a Radioisotope Thermoelectric Generator (RTG) design study which the U.S. Department of Energy commissioned Fairchild Space Company to conduct in support of the Mars Rover and Sample Return mission study under study at the Jet Propulsion Laboratory:

A. Requirements and Designs for Mars Rover RTGs, by A. Schock and V. Sankarankandath of Fairchild Space Company and M. Shirbacheh of Jet Propulsion Laboratory.

B. Thermal and Electrical Analysis of Mars Rover RTGs, by A. Schock, T. Or, and E. Skrabek of Fairchild Space Company.

C. Structural Design and Analysis of Mars Rover RTGs, by A. Schock and T. Hamrick of Fairchild Space Company.

The three papers are interrelated. Each utilizes results from the other two. Paper B contains an addition that is not included in the conference proceedings.

A. Schock

July 5,1989 


\section{CONTENTS}

A. REQUIREMENTS AND DESIGNS

Introduction $\quad \mathrm{A} 1$

Background A1

MRSR Objectives and System Elements A2

Mars Rover Design A3

RTG Requirements A4

RTG Environment A4

Design Approach A5

Heat Source A5

Thermoelectric Elements $\quad$ A6

RTG Design Options $\quad$ A6

Key Design Problem $\quad$ A7

Baseline RTG Design $\quad$ A7

Heat Source Support Structure $\quad$ A8

Multicouple RTG A9

Summary and Conclusions $\quad$ A10

B. THERMAL AND ELECTRICAL ANALYSIS

Introduction $\quad$ B1

Mass Breakdown of Baseline RTG B1

Mass of Half-Length RTG $\quad$ B2

Mass of Multicouple RTG B2

RTG Thermal Environment B3

Thermal and Electrical Analysis B3

Temperature Distribution of Baseline RTG B4

Axial Variation of Heat Flow Rates B4

Axial Temperature Profiles B5

Axial Voltage and Efficiency Profiles B5

Effect of Cooling Mode on RTG Performance B6 
Effect of Lifetime on RTG Performance B6

Effect of RTG Length on Performance $\quad$ B7

$\begin{array}{ll}\text { Multicouple RTG Performance } & \text { B7 }\end{array}$

Effect of Thermoelectric Material Properties

$\begin{array}{ll}\text { Materials Studied } & \text { B8 }\end{array}$

Assumptions B8

Thermoelectric Analysis B9

$\begin{array}{ll}\text { Results and Conclusions } & \text { B11 }\end{array}$

C. STRUCTURAL DESIGN AND ANALYSIS

Introduction $\quad \cdot \quad \mathrm{C} 1$

Structural Design $\quad$ C2

Required Preload and Resultant Stresses $\quad$ C3

Designing the Belleville Springs C6

Deformation and Stresses with Heat Source

Supported by Cantilevered RTG Housing $\quad$ C7

$\begin{array}{ll}\text { Summary and Conclusions } & \text { C9 }\end{array}$ 



\title{
REQUIREMENTS AND DESIGNS FOR MARS ROVER RTGS
}

\author{
A. Schock, V. Sankarankandath \\ Fairchild Space Company, Germantown, MD \\ M. Shirbactieh \\ Jet Propulsion Laboratory, Pasadena, CA
}

ABSTRACT

The current-generation RTGs (both GPHS and MOD) are designed for operation in a vacuum environment. The muliffoil thermal insulation used in those RTGs only functions well in a good vacuum. Current RTGs are designed to operate with an inert cover gas before launch, and to be vented to space vacuum after launch. Both RTGS are sealed with a large number of metalilc Crings. Those seals are adequate for retaining the inert-gas overpressure during short-term launch operations, but would not be adequate to prevent intrusfon of the Martian atmospheric gases during long-term operations there. Therefore, for the Mars Rover application, those RTGs must be modffied to prevent the buildup of signiflcant pressures of Mars atmosphere or of hellum (from alpha decay of the fuel). In addition, a Mars Rover RTG needs to withstand a long-term dynamic environment that is auch more severe than that seen by an RTG on an orb1ting spacecraft or on a stationary planetary lander. This paper describes a typical Rover alssion, its requirements, the environment it imposes on the RTG, and a design approach for making the RTG operable in such an environment. Specific RTG designs for various thermoelectric elenent alternatives are presented.

\section{INTROOUCTION}

In December 1988 the Department of Energy's office of Special Applications (DOE/OSA) asked Fafrchild space company to investigate RTG (Radioisotope Thermoelectric Generator) design options for powering a Martian Rover vehicle. That vehicle is a critical part of the Mars Rover and Sample Return (MRSR) nission, which is under preliminary study by NASA's Jet Propulsion Laboratory (JPL) with the support of the Johnson Space Center (JSC). JPL is responsible for the overal1 MRSR study and, among other items, for the design of the Rover vehicle.

The MRSR mission also requires a lower-power RTG for its stationary lander. However, work on this was deferred in our study, because the basic solutions worked out for the more difficult Rover application will also be applicable to the less demanding stationary lander application.

The purpose of the DOE-sponsored Fairchild study is to support JPL and JSC by providing the mission planners with information about the RTC masses and sizes for various options of differing technology readiness. Its a im is to quantify the performance improvements achievable if new technologies are successfully developed, to provide our best estimates of the required time, effort, success probability, and programmatic risk in developing those new technologies, and thus to help identify the best strategy for meeting the MRSR system goals. In addition, the Fairchild study is usefui in specifying critical design and operational requirements for integrating the RTG with the Rover and the launch vehicle (particularly cooling during orbit transfer), and in identifying what additional information JPL and JSC will need to furnish before the RTG design can be finalized. The varfous RTG design characterizations must be accurate and consistent, to permit meaningful comparisons anong the different design options. The electrical, thermal, and structural analyses of the RTGs are described in companion papers presented at this conference [1, 2]

\section{BACKGROUND}

The long-term goal of the National Aeronautics and Space Administration is to expand human presence beyond earth and into the Solar System [3]. Mars, with its potential for eventual habitability, is targeted for human exploration and colonization. A manned mission to Mars must be preceded by robotic exploration of Mars, to bridge the gap between the knowledge gained by the 1976 Viking Misston and the knowledge required for a safe and effective human journey to Mars.

The Jet Propulsion Laboratory and Johnson Space Center are jointly studying such a mission. called Mars Rover Sample Return. That study is focused on understanding the system requitrements and generating the first-order system design that meets these requirements [4]. The mission requires orbiters. landers and a Rover in Mars orbit and/ar on the Mars surface.

RTGs have been selected as the primary pover source for the surface elements of the MRSR system. They have a long and successful history of space filight, and their reliability and perfornance have been demonstrated in missions such as Pioneer, Viking, and Voyager [5]. The current-generation RTGS, however, are designed for space operation and must be modified for Mars surface operation. 


\section{MRSR OBJECTIVES AND SYSTEM ELEMENTS}

The abjective of the MRSR mission is to determine the geological, climatological and biological history of the planet Mars, and to characterize its near-surface naterfals. The mission will also provide information on the Mars environment. and test key technologies for human exploration of the planet. The mission objectives are achieved by making in-situ analyses and returning selected samples to Earth for extensive studies.

A spectrum of possfble mission and system designs has been examined against the broad science requirements [6]. These missions, which varied in launch configuration, launch date, and the various elements that constitute the mission, have been narromed down to a reference mission that consists of five systen elements: an Imaging Orbiter (IO), Communications Drbiter (CO), Rover. Sample Return Orbiter (SRO) and Mars Ascent Vehicle (MAV). The reference MRSR mission scenario and mission time line currently envisioned by the project are summarized in Figures 1 and 2 , respectively, As shown in Figure 1, the five system elements will be launched in four separate launch segments.

Figure 1. MRSR Reference Mission Scenario

IMAGING OREITER ELEMENT AO)

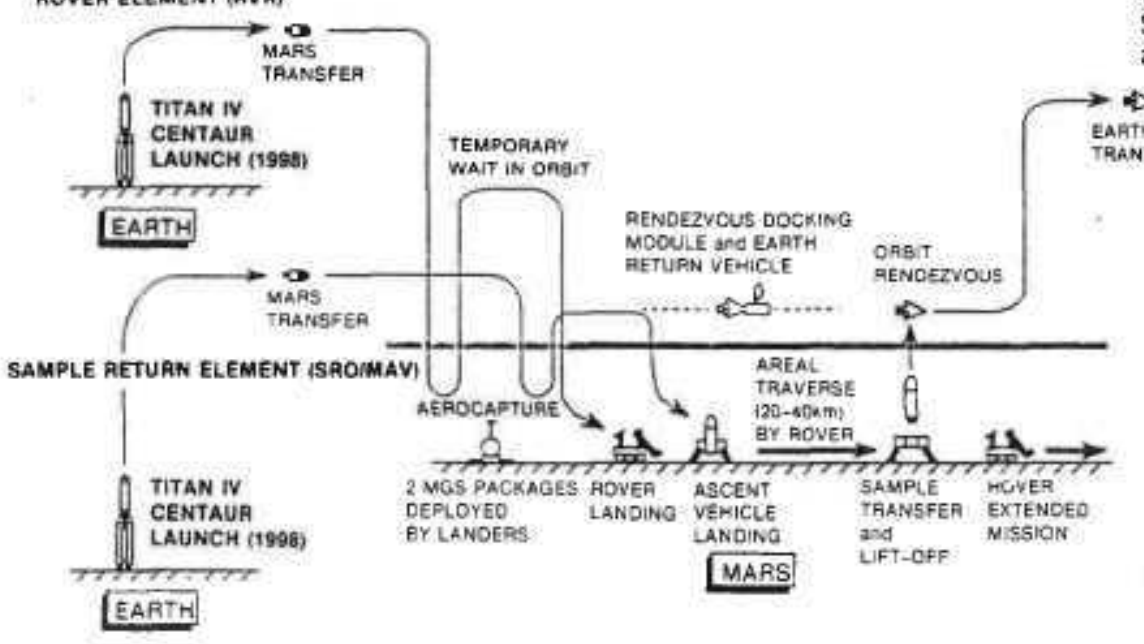

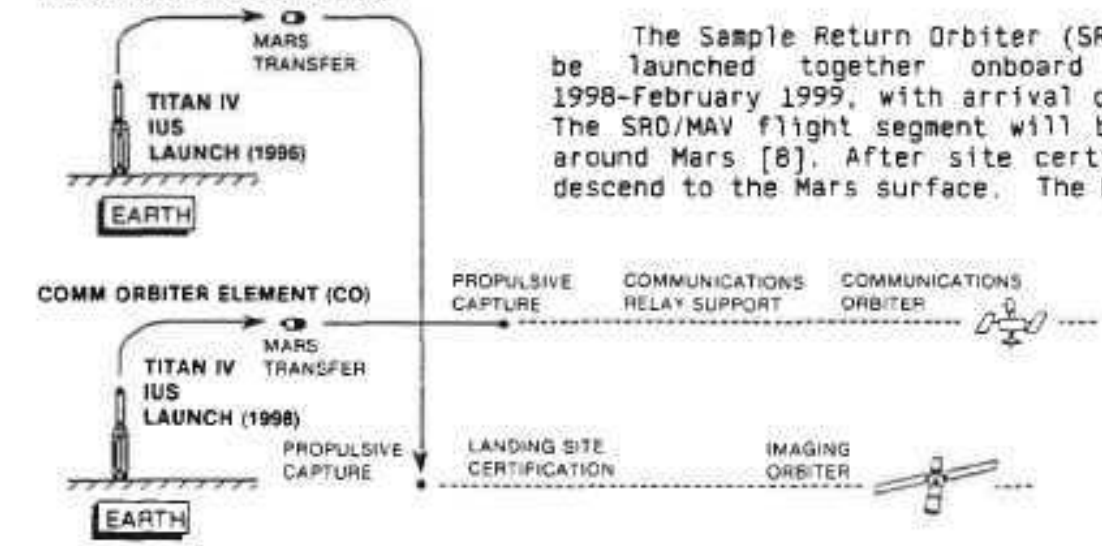

ROVEA ELEMENT (AVM) IV/IUS in October-November 1996, with Mars arrival in August-Dctober of 1997. It w111 map the surface of the planet for landing site selection and Rover Traverse Planning [7]. Nominally, the Imaging Orbiter will map sites within $39^{\circ}$ south or north of the equator. A total of ten $10 \times 10 \mathrm{~km}$ sites $\mathrm{w}+11 \mathrm{l}$ be mapped for selection of the landing site, and an area of 20 $\times 20 \mathrm{~km}$ at that site will further be mapped for Rover Traverse planning.

The Communication Orbiter $\$ 11$ provide the communication link between the Mars surface elements and Earth [7]. It will be launched in November-December 1998 aboard a Titan IV/IUS, and will be placed in a stationary orbit such that the region between $65.7^{\circ}$ south and north of the equator is covered continuously. The Rover-toEarth link is available at least $95 \%$ of every Mars Sol.

The Rover element w111 be launched aboard a Titan IV/Centaur in December 1998, with arriva? at Mars in October 1999-January 2000. The Rover will traverse the surface of Mars, perform insitu analyses, deploy science packages, select samples and return then to the ascent vehicle for delivery to Earth. Right after arrival, the Rover will also select a landing site for the MAV. The Rover design and its requirements are described in more detail in the next section. 
Figure 2. MRSR Reference Mission Timeline

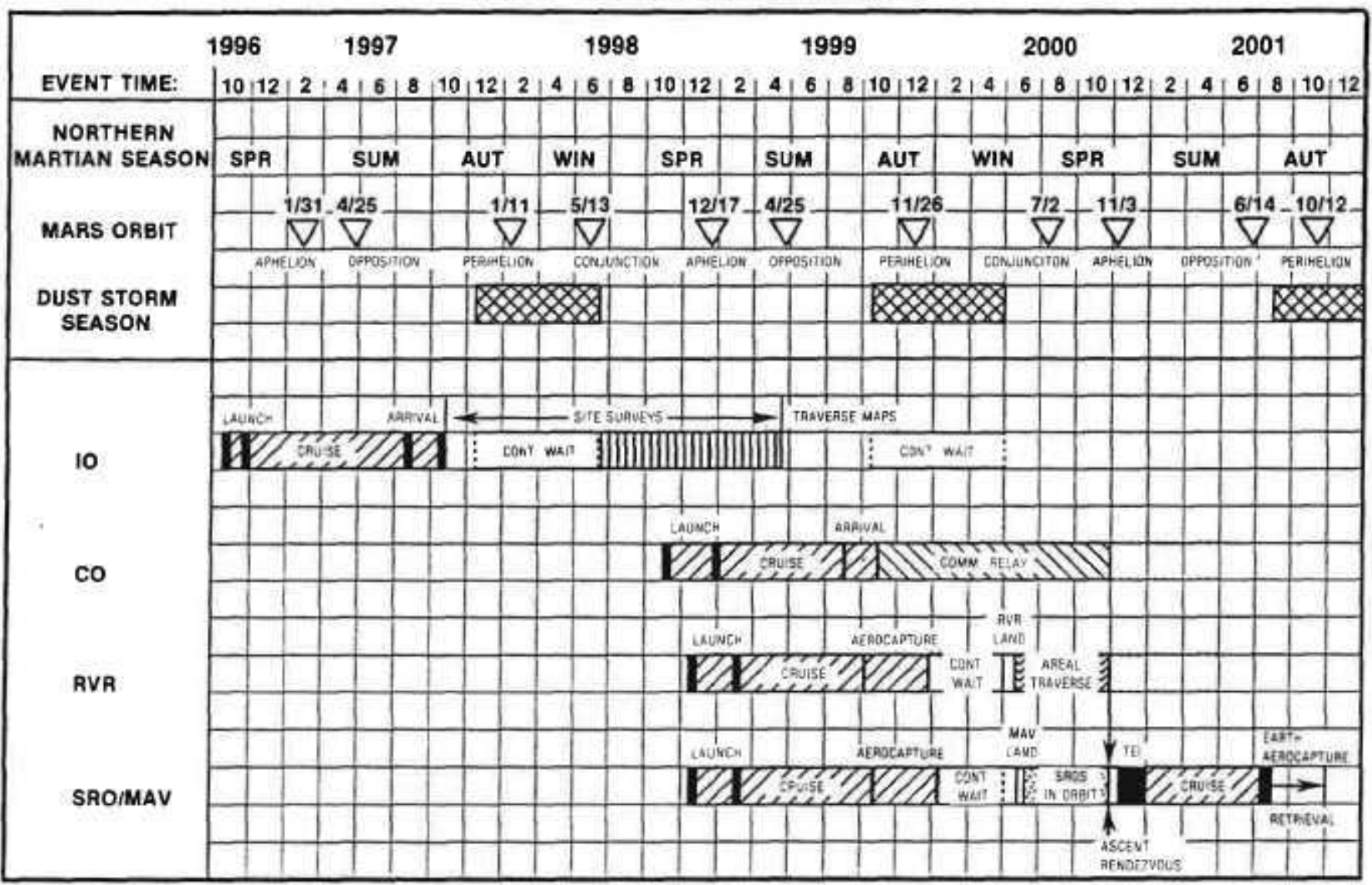

\section{MARS ROVER DESIGN}

The Rover element of the Mars Rover Sample Return mission for which the RTG study was perforned is required to traverse more than 40 kilometers and collect 100 samples from several geologically distinct sites [9]. The Rover will be equipped with semi-autonomous navigation capability, which means it can compare its surroundings with a stored map of the orbital view obtained by the Inaging Orbiter, and plan and execute a local path toward a designated point. This autonomy greatly increases the Rover's range, since it reduces the need for frequent commands fcom Earth. Theoretically, the Rover can go several kilometers without requiring intervention from Earth.

A possible Rover mobility system is a sixwheeled pantograph, with one-meter wheels that can nove across rough terrain. The Rover is further equipped with an imaging canera, multispectral imaging for science and navigation. optical microscope, spectrometers (alpha, proton. neutron, $x$-ray), electromagnetic sounders, gas analyzer, and differential scanning calorimeter The sample acquisition by the Rover will be accomplished in several stages: remote sample characterization, location and designation of interesting samples, positioning and manipulation of the Rover to acouire the sample, and preserving the samples for return to the MaV.
The Rover will return with samples to the MAV several times, where each time the distance traveled will expand as the confidence in the Rover is increased. A typical activity pattern is depicted in Figure 3 , and the Rover power requirements for a typical 1000-minute period are iliustrated in Figure $4[10]$.

Figure 3. Illustrative Rover Activity Patter

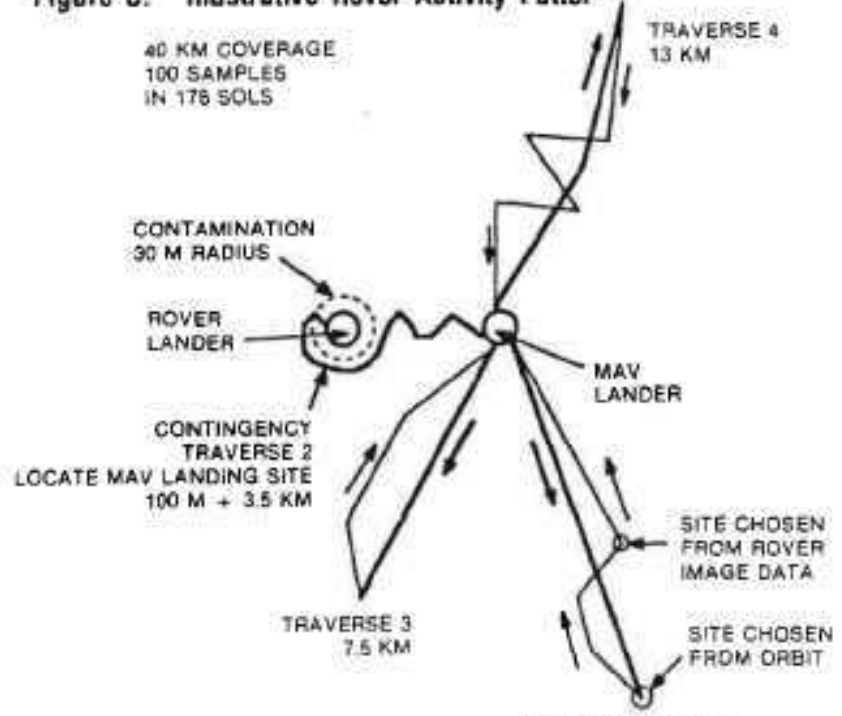

TAAVERSE 5. $16 \mathrm{KM}$ 
Figure 4. Power Demand Profile tor Typical Mars Rover Activities

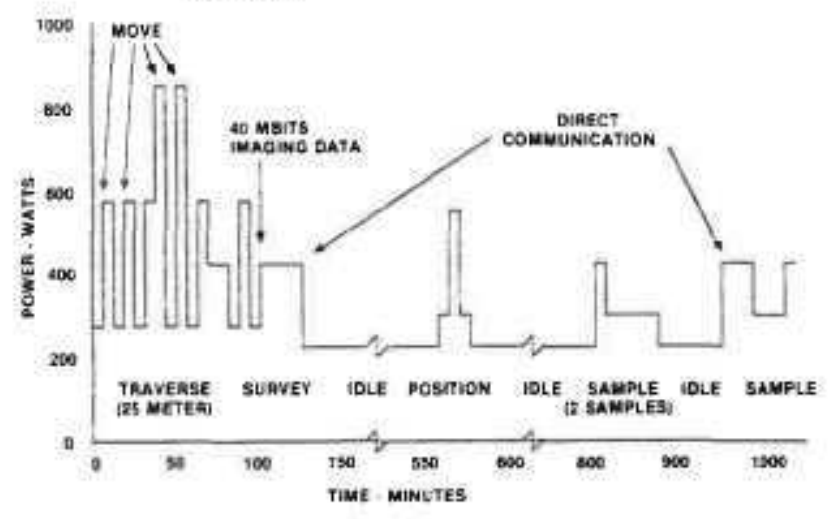

\section{RTG REQUIREMENTS}

The MRSR wission calls for the Rover to operate for four years after launch. The launch is assumed to occur three years after fue? encapsulation, and to be preceded by one year of full-temperature operation of the thermoelectric converters. Thus, by the end of the mission the RTG's fuel will have decayed for seven years, and its converters w111 have operated and degraded at full temperature for five years.

As illustrated in Figure 4 , the Rover has an average power requirement of 500 watts, with peak power denands of over one kilawatt when the Rover is climbing a slope or in the process of sample acquisition. The RTGS will be designed to provide continuous power with an output of 500 watts at the end of mission, and these will be supplemented by rechargeable batteries for meeting the peaks of higher power demand. The high-power-density batteries will be recharged by the RTGs during the idle mode of the Rover.

Figure 5. Ilustrative Rover Design with Four 125-Watt RTGs

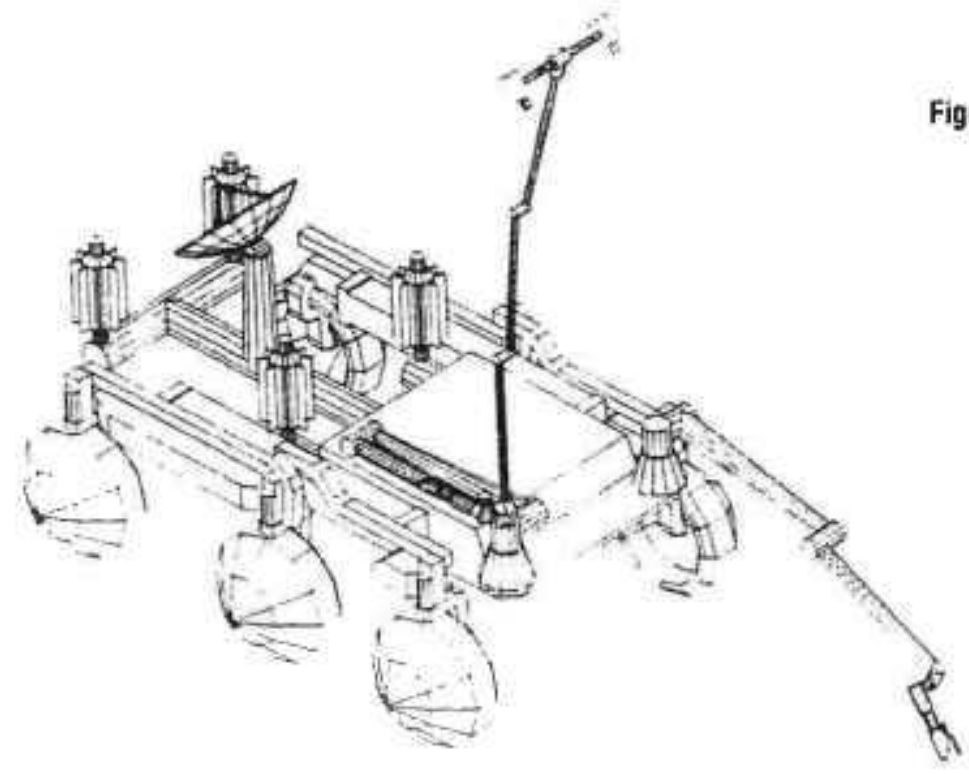

The number and location of RTGS on the Rover is very critical and require trade-off analysis. The Rover designers prefer several small RTGs distributed around the vehicle. This arrangement helps in the load distribution and also facilitates use of the RTGS waste neat for thermal management of the Rover body and electronics bays. Also, shorter RTGs are less likely to block other Rover instruments and/or antennas. On the other hand, longer RTGs offer a higher specific power, because of decreased end losses and weights. They also are less likely to obscure the view of each other's radiators to space. At present, two concepts for integrating the RTGS with the Rover are undergoing evaluation, one esploying two 250-watt RTGs, and one employing four 125-watt RTGs mounted on top of the Rover. The latter integration schene is illustrated in Figure 5 .

\section{RTG ENVIRONMENT}

Both the Rover and Mars environments present new challenges to the RTG designer. Previous RTGs (MHW, GPHS) were designed primarily for operation in microgravity and in a high vacuum after leunch. The Rover and Mars environments are more difficult. mechanically, thermally, and atmospherically.

From the dynamic-environment point of view, the Rover RTG has to withstand launch, entry, landing, and traverse loads that occur at different times in the 1 ife of the mission. These loads cannot be accurately determined unt $t 1$ the spacecraft and Rover structures are better defined. In the absence of such definition, the RTG design study was based on 3-axis design loads of $25 \mathrm{G}$ during Earth launch and $15 \mathrm{t}$ during and after Mars landing. for the duration of the Mission.

The Rover RTG also has to operate in a temperature environment that varies much more than that seen by most previous RTGs. During entry into the Martian atmosphere, the Rovermounted RTGs are enclosed in a protective aeroshe11, as illustrated in Figure 6. Therefore,

Figure 6. Rover with RTGs and Lander Enclosed in Aeroshell
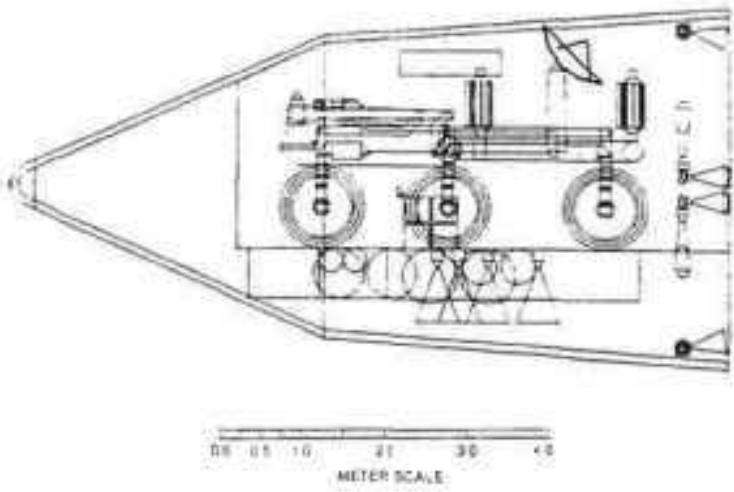
during Earth launch and cruise to Mars, the RTGS require an auxiliary cooling loop to transfer their waste heat to radiators. During Mars operation, when the RTGs are cooled by radiation, diurnal and seasonal temperature fluctuations cause their effective sink temperature to vary from a minimum of $140^{\circ} \mathrm{K}$ to a maximum of $300^{\circ} \mathrm{K}$.

The most difficult probiem imposed by Mars surface operations is the presence of an external atmosphere [11]. The thermoelectric converter elements in the RTG are embedded in multifoil thermal insulation, to minimize heat losses from the hot heat source to the cool generator housing. Thus, the insulation forces most of the heat through the thermoelectric legs.

Multifoil insulation performs well in the absence of conducting gases, but degrades rapidly when such gases are present. Moreover, at the projected operating temperatures even small amounts of some of the Martian gases would react with the converter's materials and degrade its performance. Therefore, the thermoelectric converter has to be sealed off from the Mars atmosphere and fron the helium that is continuousiy generated by alpha decay of the isotope fuel.

\section{DESIGN APPROACH}

The first decision is the selection of the thermoelectric materials. The basic choice is between TAGS ( $\mathrm{Te}-\mathrm{Ag}-\mathrm{Ge}-\mathrm{Sb}$ ) and SiGe (with or without GaP additives). TAGS was used on earlier misstons, including the 1976 Viking mission to Mars. Sile is used in all recent and current space RTGS, including LES-8/9, Voyager, Galileo, Ulysses, and the more advanced Mod RTG under deveiopment by $\mathrm{DOE}$.

TAGS thermoelectrics operate at lower hotand cold-junction temperatures than site. Their hot-junction temperatures are far below the temperature capability of current radioisatope heat sources. Therefore they wouid not take proper advantage of that capability. SiGe elements come much closer to matching the heat source temperature limits.

TAGS thermoelectric elements have only been used in spring-loaded RTGs. Such RTGs tend to be much heavier than radiatively coupled RTGs, particularly since they use relatively bulky and inefficient fibrous insulation. By contrast, the thermoelectric elenents in SiGe RTGs are heated radiatively. Thus, they do not contact the heat source, and no spring loading is required. They are insulated with lighter, more compact, and more efficient multifoil insulation.

Since TAGS elements operate with much lower hot-junction temperatures than sige, they also demand correspondingly lower cold-junction temperatures for efficient operation. This would require relatively large and heavy radiators. The lower cold-junction temperatures would be particularly disadvantageous in the present application, because they would make the RTG power output more sensitive to the large seasonal and diurnal temperature fluctuations on the Martian surface.
For these reasons, the Rover RTG design study is based on the use of SiGe rather than TAGS elements.

To minimize the need for new developments and allow the use of existing fabrication drawings and test fixtures, the initial design studies were conservatively based on: standard General Purpose Heat Source modules, which have been developed and safety-qualified for the Galileo mission; standard-size unicouples, developed and extensively $1+f$ fetested for the Voyager and Galileo missions; standard-size multicouples, lifetested in DOE's Mod-RTO program: and thermoelectric performance parameters and degradation rates that have been demonstrated in extended tests of SiGe unicouples and SiGe/GaP multicouples.

\section{HEAT SOURCE}

OOE has spent approximately ten years and $\$ 40-50 M$ on the develophent [12] and safety qualification [13] of the General Purpose Heat Source (GPHS), for initial deploynent on the Gallleo and Ulysses space exploration missions. As a result of that effort, this heat source is extremely well characterized, much more so than radioisotope heat sources used on previous space missions.

The heat source is modular, and a sectioned view of a standard 250-watt module is shown in Figure 7. Each GPHS module contains passive safety provisions against fuel release for all credible accident conditions. As shom, each module contains four iridium-clad $\mathrm{Pu}^{238} \mathrm{O}_{2}$ fuel capsules surrounded by graphitic components, including an aeroshell designed to withstand reentry ablation, a thermal insulator to avoid excessively high $\mathrm{clad}$ temperatures during the reentry heat pulse and excessively low clad temperatures at earth impact, and an inpact shell to help absorb impact energy and reduce fuel capsule deformation during earth impact. Viewed from the outside, each GPHS module is a graphite brick of roughly $2 \times 4 \times 4$ inches. This module was used as the buflding block for all RTC designs presented in this paper and its companions $[1,2]$.

Figure 7. General-Purpose Heat Source Moduie (250 Watt) Sectioned At Midplane

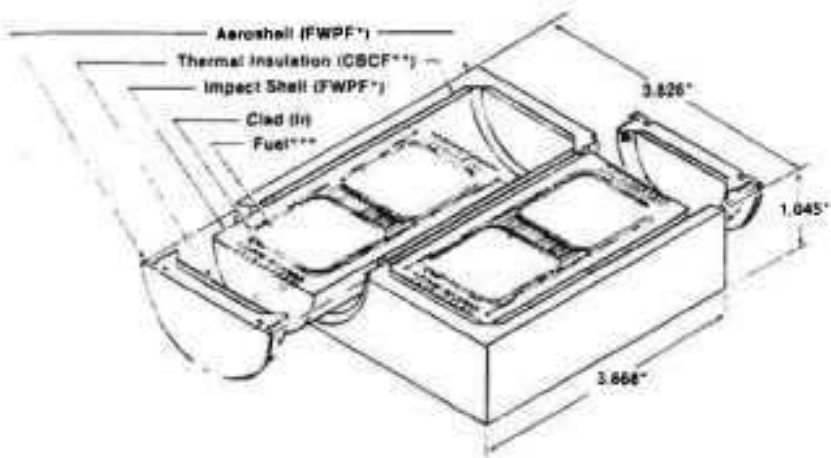

\footnotetext{
-Fine-Weave Pierced Fabtic, a $80 \%$-dense $3 D$ carbon-carbon composite *Carbon-Bonded Carbon Fibers, a 10\% dense high-temperature insuttor *62.5-wattra PuO, pelie!
} 


\section{THERMOELECTRIC ELEMENTS}

The present study is based on two alternative types of thermoelectric (TE) elements: unicouples and nulticouples. Both use SiGe-based thermoelectric natertals. The standard unicouple. Which was used in the MHN RTGS flown on the voyager and LES B/9 missions and in the GPHS RTGs for the Galtieo and Ulysses missions, is depicted in Figure 8 . The $P$ and $N$

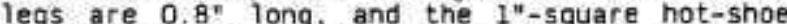
collects the heat radiated by the heat source and delivers it to the TE legs. The cold end of the unicouple is bolted to the RTG housing, and the electrical connections between couples are made on the inside of the housing.

Figure 8. Unicouple

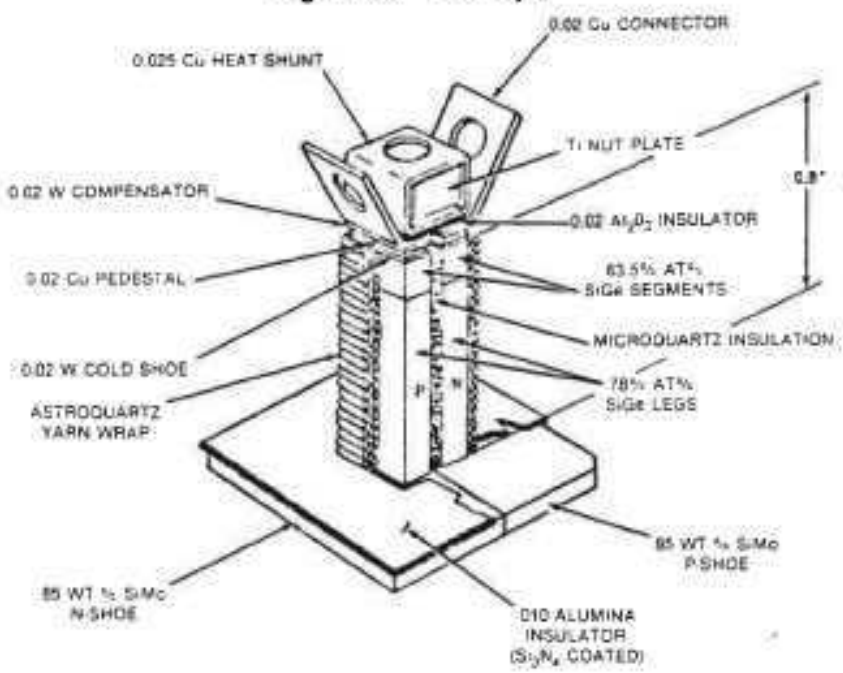

The standard multicougle, developed for the Mod-RTG, is depicted in Figure 9. It differs from the unicouple primarily in that instead of two TE legs each TE element has 40 legs, which together with its hot and cold electrodes form 20 series-connected couples. The standard multicouple legs are only $0.3^{n}$ long, compared to the unicouple's $0.8^{\prime \prime}$ leg length. This reduces the weight of the thermal insulation and of the RTG housing.

Figure 9. Multicouple Cross-Section

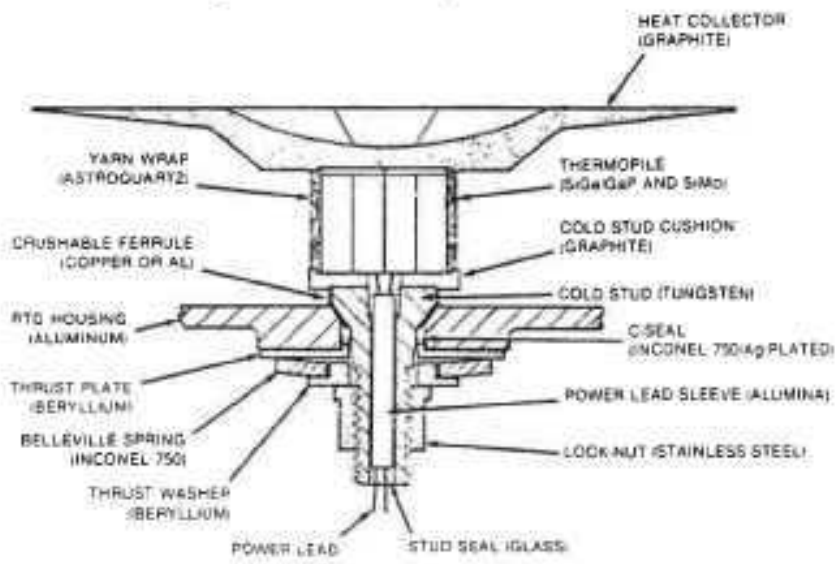

The multicouple's legs are bonded to, and insulated from. each other by $0.002^{n}$ glass layers. The heat collector, approximately $2^{\text {"n }}$ square, is made of graphite. In contrast to the unicouple, the multicouple's mounting stud and power leads penetrate through the RTG housing. and electrical connections between multicouples are made on the outside of the housing. As will be seen, these differences affect the Rover RTG design.

\section{RTG DESIGN OPTIONS}

Initial RTG designs were conservatively based on standard unicouples and nulticouples. using demonstrated thernoelectric performance levels and degradation rates. The standard unicouples and multicouples are the only SiGe TE elements for which an extensive experimental data base exists. Large assemblies of SiGe unicouples have been used in RTGS for a number of flight missions (LES 8/9, Voyager, Galileo, Ulysses), and have demonstrated stable performance with moderate and predictable degradation rates for periods in excess of 100,000 hours.

Multicouples operating at the required hotjunction temperature $\left(1000^{\circ} \mathrm{C}\right.$ ) have a much smaller data base. Their development was initiated in the late 1970 s [14], their present design was defined in 1983 [15], and their most successful test to date (of an assembly of eight nuiticouples) was a 6000-hour run at Fairchild completed in Decenber 1988. when it was temporarily interrupted for a planned modification of the test fixture and for withdrawal of three of the multicouples for destructive exanination.

During the 6000-hour test, the six multicouples that operated with a positive bias with respect to the RTG housing exhibited very stable performance, but the two multicouples that were negatively biased exhibited unacceptable degradation rates. This negative-bias problem had been first identified by Fairchild tests more than two years earlier. Although GE has been working diligently to solve the problem, the solution is not yet in hand. Until it is, they can only be used if all multicouples in the RTG are positively biased. Fortunately, the RTG can be configured to achieve that condition, albeit at sone mass penalty.

Beyond the standard unicouple and multicouple, a number of RTG designs based on more advanced thermoelectric elements were also defined and analyzed. The postulated advances were in element geosetry and/or in naterial performance. They ranged from relatively minor changes to major advances. For the nost advanced option, there is no experimental basis nor clear development pathway. It was included in the study to define the posstbie performance benefits if the postulated advances were in fact achieved.

Detalled descriptions of the advanced design aptions and the resultant performance inprovements are presented in the next paper [1] in these proceedings. This summarizes and discusses the results of the thermal. thermoelectric, and electrical analyses of the 
various design options. The present paper deals primarily with the basic design approach, which is the sane for all of the design options. Thus, the two basic designs described in this paper apply to all options of interest.

\section{KEY DESIGN PROBLEM}

The key problem in designing an RTG for Mars is the need to vent the helfum generated by the fuel's alpha decay to the outside without allowing the Martian atmosphere to enter into and build up harmful quantities within the RTG. In the 1976 Viking mission to Mar5, the 35-watt RTGs used fibrous insulation, which is much less effective than multifoil and leads to a substantially higher system mass. However, the more efficient and compact muitifoil insulation used in the present study is only effective in a good vacuum ( $<1$ tor $r$ ). But the existing GPHS-RTO and Mod-RTG both use a large number of metal Cring seals. Such seals are adequate for retaining the inert cover gas during the short launch period, but not for preventing intrusion of the Martian atmosphere during extended Mars operations.

To prevent helium pressure buildup inside the RTG above I tor , the use of a selective vent has been considered. But to maintain an internal helium pressure of less than one torr, such a vent would have to have a very low flow resistance. However, a low-flow-resistance vent would allow appreciable back diffusion of Martian gases into the RTG. This would be unacceptable unless these Martian gases were effectively gettered as soon as they entered the RTG. Even small quantities of Martian gases $\left(\mathrm{CO}_{2}, \mathrm{CO}, \mathrm{O}_{2}\right)$ would result in deleterious reaction with the RrG materials.

Since the system of selective vent and effective getter has not yet been demonstrated. the present study is based on RTG designs with an evacuated annular converter, sealed off from the both the internal helium and the external Mars atmosphere, as illustrated in the next figure.

\section{BASELINE RTG DESIGN}

Figures 10 and 11 show cross-sectional views at offferent. locations of the baseline RTG. Figure 10 shows two horizontal sections (AA and $B B$ ) and Figure 11 shows a vertical section (CC). Section $A A$ shows a horizontal cut through the active region of the RTG, 1.e... through the nidplane of a heat source module and through the midplane of a ring of thernoelectric unicouples. The rest of Figure 10 represents Section BB. It shows a horizontal cut through the upper and lower heat source support structure. The locations of sections $A A$ and $B B$ are indicated in Figure 11 .

Figure 11 shows a vertical cross-section (CC) of the RTG. As indicated in Figure 10, the left half of section CC shows a section that is perpendicular to the axes of the fuel capsules in the heat source stack and through two columns of thernoelectric unicouples mounted on the housing; and the right half of Section CC shows a diagonal cut through the heat source stack. The location of section CC is shown in Figure 10.
In Figures 10 and 11 two different shading patterns are used to designate the helium volune inside the heat source canister and the Martian atmosphere outside the RTG housing. The intervening annular converter is evacuated, and is separated from the helium by the heat source canister and from the Martian atmosphere by the RTG housing.

Figure 10. Baseline RTG. Horizontal Cross-Section (B-B)

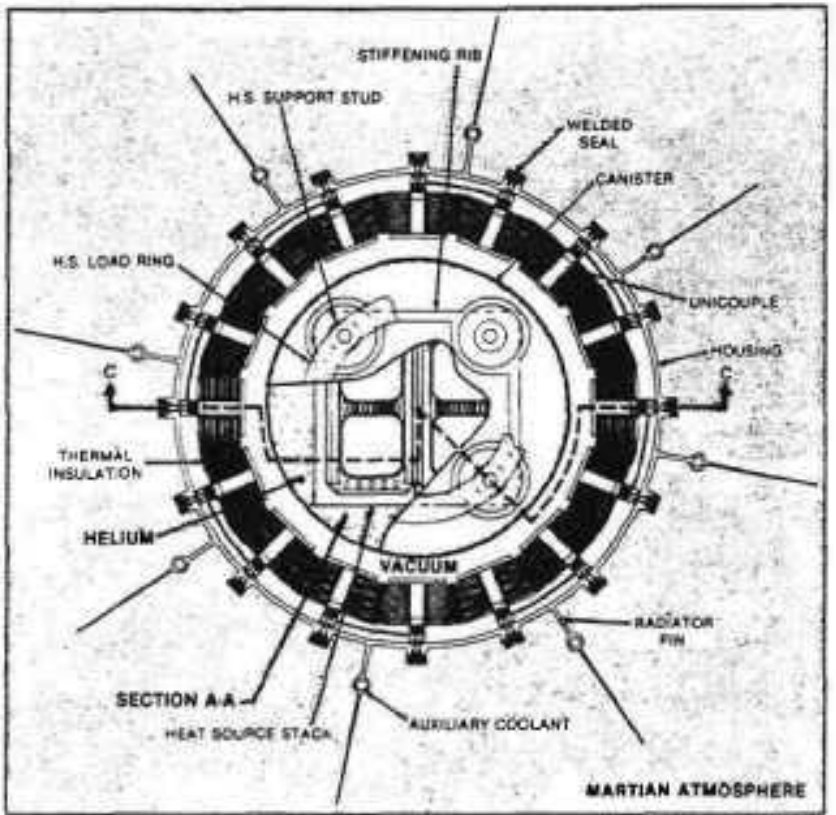

Figure 11. Basaline RTG, Vertical Cross-Section (C-C)

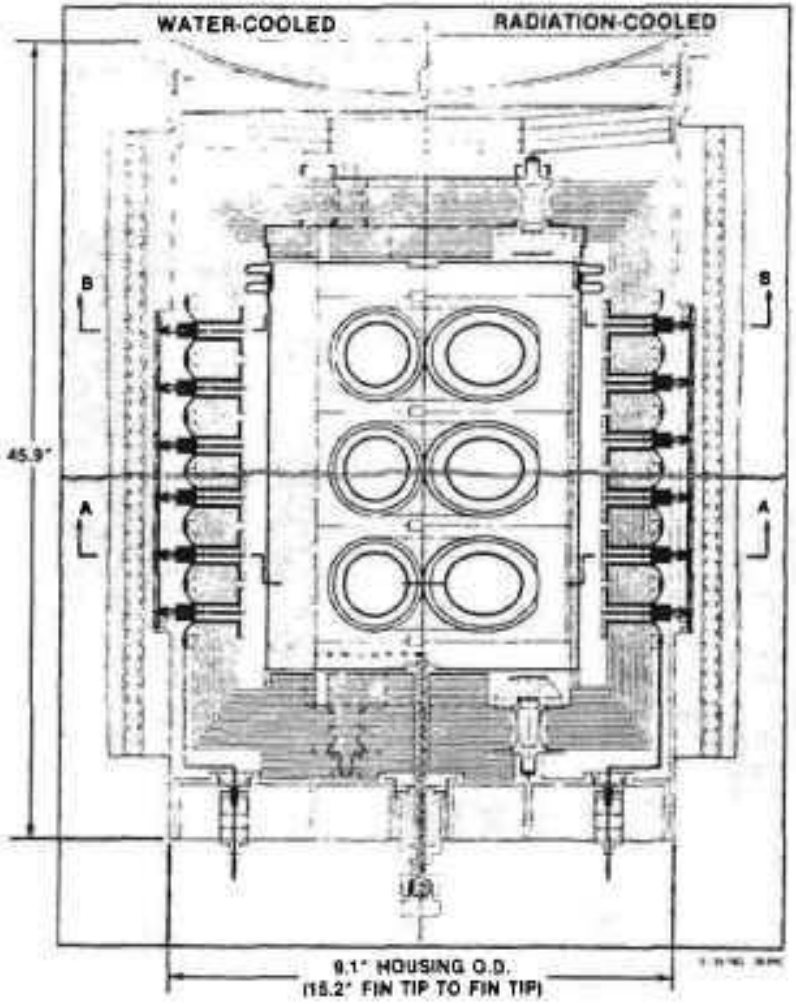


Figure 10 shows that, as in the Galfleo RTG, there are 16 unicouples around the circumference, and these are bolted to the housing at 22.50 intervals. In the Galileo RTG the mounting bolt holes of its 572 unicouples are sealed by metal C-rings, but these would be inadequate for preventing inflow of the Martian atmosphere over mission life. In the present design, the boit holes are hermetically sealed by 16 aluminum cover strips welded to the aluminum housing ribs.

The heat source of the 250-w(e) baseline RTG consists of a stack of 18 GPHS modules, but for improved visibility only three are depicted in Figure 11. As seen, there are two rings of 16 unicouples for each of the 18 neat source modules, for a total of 576 unicouples per RTG. As shown. the baseline RTG has a height of $45.9^{\prime \prime}$. a housing diameter of $9.2^{\prime \prime}$, and a radiator tipto-tip span of $15.2^{\mathrm{H}}$.

The unicouples in the baseline RTG are embedded in a $0.8^{\text {" }}$-thick layer of thermal insulation, consisting of 60 alternating layers of $0.0003^{\prime \prime}$-thick molybdenum pofl and quartz cloth. This type of insulation, which was used in the MHW and Galileo RTGs, is constderably heavier than multifoll insulation with zirconiaparticle spacers used in the Mod-RTG.

As in the Galileo RTG, there are eight radiator fins and each fin contains an auxiliary cooling tube. The auxiliary coolant is used to controi the RTG housing temperature during launch and during transit to Mars, while the RTG is enclosed in the aeroshell that protects the Rover and lander during their entry into the Martian atmosphere. After entry, the aeroshell is jettisoned, the auxiliary cooling is discontinued, and the RTG is cooled primarily by radiation from the fins. Convective cooling by the Martian atmosphere, even on a cold windy day. makes only a relatively minor contribution to heat rejection.

The trapezoidal radiator fins shown in Figure 10 have a root thickness of $0.066^{\prime \prime}$ a tip thickness of $0.015^{\prime \prime}$, and a root-to-tip height of 3". These dimensions are merely fllustrative. The optimum fin dimensions will be determined by a detailed radiator design optimization, described in companion papers $[1,2]$ in these proceedings.

Figure 11 shows the series connections between the unicouples and the RTG terminals at the botton of the converter. As shown, the RTG requires bimetallic joints from aluninum to stainless steel and to Kovar. Such bimetallic joints have been formed by explosive bonding. and have undergone extensive thermal-cycling tests. Their small diameter should enhance their reliabllity. The Kovar-aiunina-Kovar meta1ceramic seals form the feedthroughs for the electrical terninals. Figure 11 also depicts the vent tube and viton seal through which the helium from the canister is vented to the Martian at mosphere.

As mentioned earlier, the baseline RTG has 36 rings of 16 unicouples, or a total of 576 unicouples. The 576 couples are connected in two identical (180-degree) serfes-paral1el networks. as illustrated in figure 12. There are 144 couples in series, to generate the desired 30-volt output. The couples in each network are paraliel-connected in groups of two, to enable the RTG to continue operation in case of singlepoint fallures. A7ternatively, the 576 couples could be connected in a single $144 \times 4$ seriesparallel network for even higher reliability.

Figure 12. Schematic Circuit Diagram of Baseline RTG

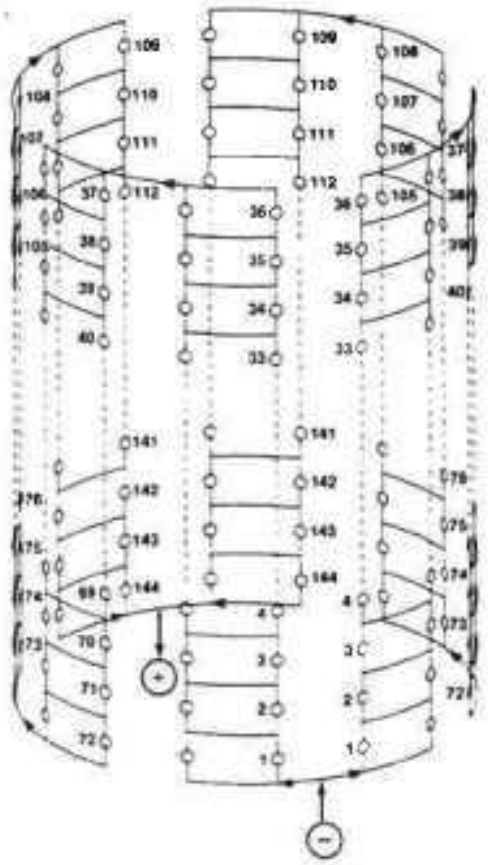

\section{HEAT SOURCE SUPPORT STRUCTURE}

One of the most critical issues in designing an RTG with stacked heat source modules is the scheme for supporting that stack. The modules must stay together during transverse G-loads. But for safety reasons, it is desired that the modules separate during reentry, to obtain a low impact velocity. The method of achieving this in the Rover RTG is 11lustrated in Figure 10 and 11.

The heat source stack is only supported at its ends, and a large $(5500-1 \mathrm{~b})$ axial preload is required to hold the stack together ouring launch under the assumed $25-G$ transverse load. The axiai preload is applied directly to the ends of the stack, via the canister's end caps. The canister's side wll plays no structural role; it is merely a helium container, and is thin enough to burn off during reentry.

The lateral support and axial preload force on the heat source is applied at each end of the canister by a set of four low-conductance Inconel studs and zirconia insulators. similar to those used in the Galileo RTG. Two of the eight studs are vistble in the diagonal cross-section, at the right of Figure 11. As shown in Figure 10, each of the canister's end caps contains an integral square structure. These serve to stiffen the end caps and to spread the axtal load from the four 
support studs to the four edges of the heat source stack. As indicated in the left half of Figure 11, the square load-spreading stricture

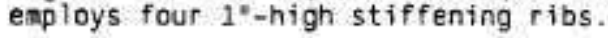

The tops of the four studs are bolted to a titanium load ring, which is laterally supported and axially loaded by a set of three nested Belleville springs nade of $0.2^{\prime}$-thick titanium, Three springs are used in order to generate the required preload without exceeding the allowable stress in the springs. The I.D. of the bottom spring bears against the load ring, and the $0, D$. of the top spring bears against a titanium set ring that is threaded to the I.D. of the aluminum housing. After the load is set, rotation of the set ring is prevented by pins protruding from the RTG's aluminum cover. That cover serves only as a pressure dome, and has no other structural function.

The support structure at the bottom of the heat source stack uses an identical set of Inconel studs and zirconia insulators. But there are no springs, and the studs are nounted directiy on the RTG's aluminum base plate. The base plate employs 1"-high radial and circumferential ribs to supply the required stiffness.

Clearly, the heat source stack is ultimately helo together by the RTG's low-melting aluninum housing. When that housing and the thin canister burn away during reentry, the heat source modules are free to disperse and impact individually.

The Belleville springs must - supply sufficient force to enable the heat source stack to withstand the lateral G-loads during launch while the RTG fins are water-cooled. Once the Rover aeroshell is discarded after entry into the Martian atmosphere, the RTG is cooled radiatively for the balance of the nission.

When changing from water-cooling to radiation cooling, the RTG housing temperature rises about $100^{\circ} \mathrm{C}$ (on a summer day). This causes a differential growth of about $0.100^{\circ}$ in the length of the high-expansion aluminum housing relative to the low-expansion graphite heat source stack, with a corresponding increase in the Bellevilie spring length and drop in spring force. In RTGs for other missions, the magnitude of the spring force is only important briefly during launch. In the case of the Rover RTG, the springs must still provide sufficient force after relaxation to nold the heat source together during Mars traverses for the balance of the mission.

The left half of Figure 11 depicts the water-cooled RTG during launch and transit to Mars, assuming a wall temperature of $100^{\circ} \mathrm{C}$ for the auxiliary coolant tubes. The right half of the figure depicts the radiatively cooled RTG on a hot Martian day. The top of the figure depicts the differential thermal growth and the resultant spring relaxation. The springs were designed to provide the axial forces required to resist lateral loads of $25 \mathrm{G}$ during launch and $15 \mathrm{G}$ on Mars.

\section{MULTICOUPLE RTG}

Horizontal and vertical cross-sections of an RTG employing standard-size multicouples are shown in Figures 13 and 14 . The multicouple-RTG design depicted in those figure are generally sinilar to the unicoupie-RTG design shown in the analogous figures 10 and 11 , and only the significant differences will be mentioned.

Figure 13. Multicouple RTG, Horizontal Cross-Section (B-B)

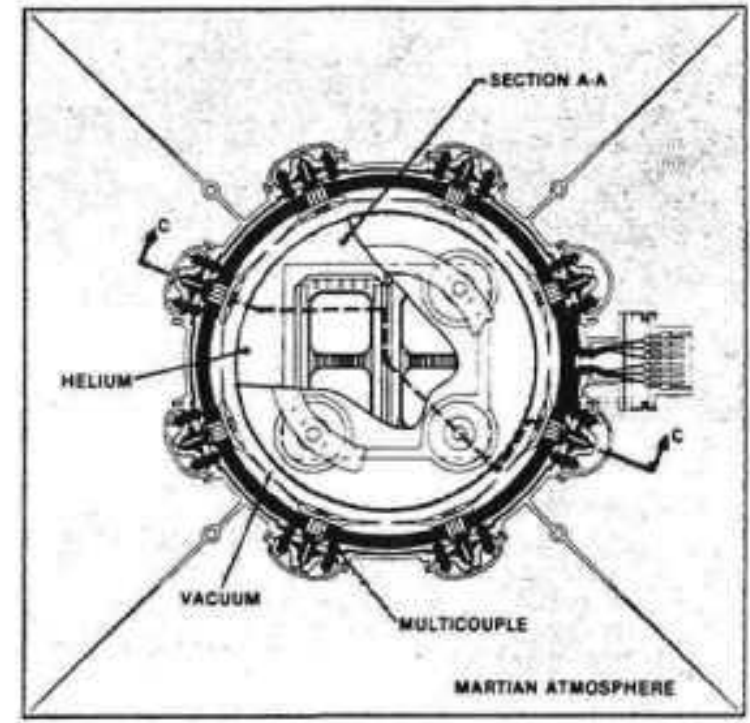

Figure 14. Multicouple RTG, Vertical Cross-Section (C-C)

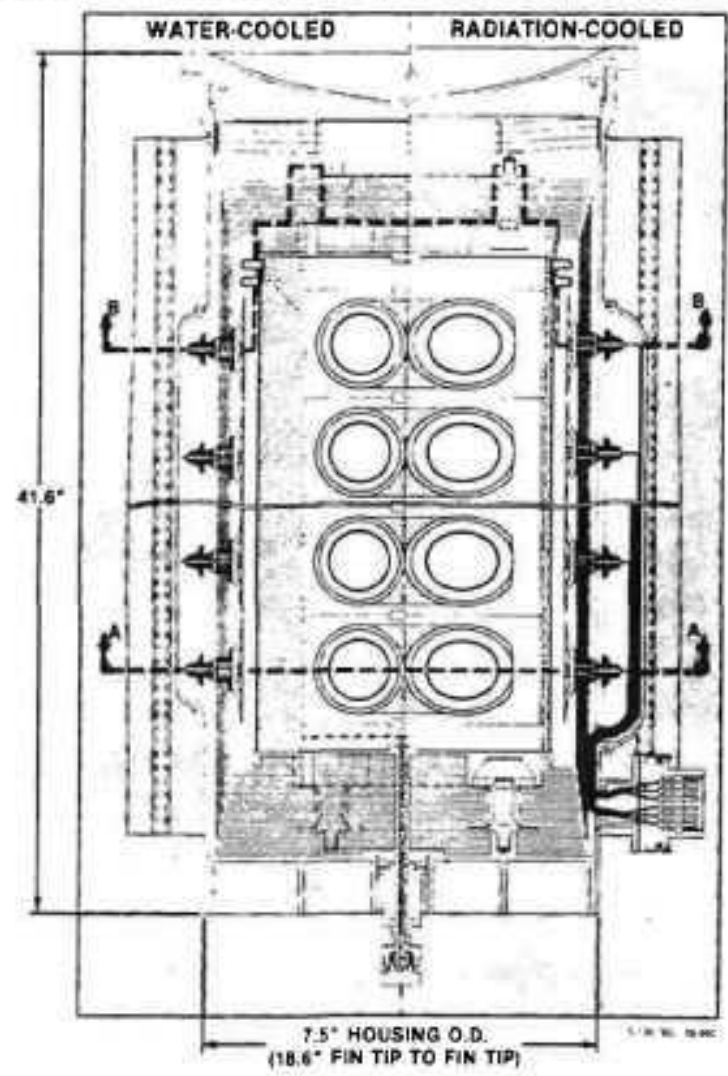


As in the Mod-RTG, there are eight multicouples per horizontal ring, and only one multicouple ring per heat source module. For a 250-watt(e) power output, the RTG has 16 heat source modules. Thus, there are 128 multicouples per RTG, or $22 \%$ as many TE units as in the unicouple RTG.

In the Mod-RTg the multicouple mounting holes are sealed by conical metal ferrules, but these would be inadequate for preventing inflow of the Martian atmosphere during long-tern operations on Mars. Therefore. the bolt holes in the present design are hermetically sealed by efght semi-cylindrical aluminum seal covers weided to the alusinum housing hubs.

In the standard multicouple design, the leads pass through the housing wall, and are series-connected on the outside. To preserve hermeticity in the present RTG design, the series leads are passed back to the inside of the housing via insulated studs, for internal series connections between the eight multicouples in each ring.

As in the Mod RTG, the eight multicouples are embedded in a $0.3^{\prime \prime}$-thick layer of thermal insulation, consisting of 60 layers of $0.0003^{n}$-thick molybdenum folis, separated fros each other by zirconia spacer particles. This type of insulation is not only lighter than the standard unicouple insulation, but its lower thickness also leads to significant weight saving due to the consequent reduction (from $9^{\prime \prime}$ to $7.5^{\prime \prime}$ ) in housing diameter.

The option shown in Figure 13 has four radiator fins. The alternative of eight fins was also analyzed. The analytical results showed that the 8-fin option yields a higner specific power.

The series connections between thernoelectric elements are horizontal rather than vertical. The multicouple RTG design is nodular [14], because each horizantal ring produces the desired RTG valtage (30V). Multicouples have operated stabiy for 6000 hours, before the tests was interrupted for fixture nodification. But stable operation was only achieved when the nulticouples were at a positive bias with respect to the RTG housing. Therefore, the Rover RTG is designed for positive bias operation of all multicouples. To avoid the possibility of single-point fallures, this requires that the leads from each of the sixteen current loops be separately brought out to the power conditioning unit through a multipin terminal, as shown at the right of Figures 13 and 14 .

\section{SUMMARY AND CONCLUSIONS}

The current multifoil-insulated GPHS-RTG and Mod-RTG designs can be modified to operate in an environment with an external atmosphere (e.g.. Mars). This can be done while the helius generated by the fuel's alpha decay is vented to the external atmosphere. The use of novel selective vents and high-capacity getters is not, required. The Rover RTGs can be built fron standard and proven GFHS modules and standard sige unicouples or $51 \mathrm{Ge} / \mathrm{GaP}$ multicouples, using demonstrated thermoelectric material perfornance parameters. Rover's 500 -watt power requirement. can be satisfied with two 250-watt or four 125-watt RTGs, whose sizes are compatible with currently envisaged Rover designs. An auxiliary cooling loop (e.9., water and antifreeze) will be required to cool the RTG while it is within the Rover's aeroshell during launch and transit to Mars.

As in present RTGS, the modular heat source stack in the Rover RTG is held together by axial load springs. The Raver RTGs do not require midspan supports. The Belleville load springs are designed to hold the heat source together in the water-cooled RTG under 25-G loads during Earth launch and Mars entry, and in the radiationcooled RTG under $15-G$ loads during subsequent Mars operations. Basic designs have been prepared for both unicouple RTGs and multicouple RTGS. These designs apply both to current TE elements and to elements of advanced designs and materials.

Detailed analyses to compare the RTG mass and performance for a variety of designs and thermoelectric materials properties are described in companion papers $[1,2]$ presented at this conference. The principal conclusions derived from the results are:

- The baseline RTG has a mas5 of $63.2 \mathrm{~kg}$, with a power output of 278 watts BOM and 256 watts EOM when radiating to a $300^{\circ} \mathrm{K}$ Mars envtronment.

- The baseline RTG has a BOM/EOM system efficiency of $6.32 / 6.01 \%$, and a specific power of $4.74 / 4.37$ watts $/ \mathrm{kg}$.

- The conbined effect of fuel decay and thermoelectric material degradation during the four-year nission reduces the power output by $8 \%$.

- The RTG can deliver full operating power during its water-cooled cruise to Mars.

- The power output of the radiatively cooled RTG is essentially independent of the Martian temperature.

- The mass of four 125-watt RTGS is $6 \%$ higher than that of two 250-watt RTGs.

- The specific power of the four 125-watt RTGs is $7 \%$ lower than that of the two 250 -vatt RTGS.

- The 250-watt baseline RTG has a length of 45.9 inches, and the 125-watt unit has a length of 41.6 inches. Efther length appears to be compatible with currently envisaged Rover designs.

- A 250-ratt RTG using standard multicouples is 23\% 1ighter, 9.4\% shorter, $7 \%$ more efficient, and has a $23 \%$ higher speciftc pover than the baseline RTG using standard unicouples. 
- The RTGS'fuel loading and mass can be significantiy reduced by employing thermoelectric materials with higher figures of merit, when these become available.
The ultimate design and material selections will represent a trade-off between minimizing the RTG mass, to help meet the Rover systen design goals of NASA/JPL, and minimizing the need for new technology, to reduce the development costs and programatic risks of DOE.

\section{REFERENCES}

(1) A. Schock, I, Or and E. Skrabek, "Thermal and Electrical Analysis of Mars Rover RTGs." 24th Intersociety Energy Conversion Engineering Conference, 6-1] August, 1989.

[2] A. Schock and T. Hanrick, "Structural Design and Analysis of Mars Rover RTGs." $24 \mathrm{th}$ Intersociety Energy Conversion Engineering Conference, 6-11 August, 1989.

[3] Statement before the Committee on Energy and Natural Resources, United States Senate by Dr. Robert Rosen, Sept. 13, 1988.

[4] J.D. Bourke, J.H. Kwok, A. Friedlander, "Mars Rover Sample Return Mission." AIAA89-0417, 27th Aerospace Sc1ence Meeting January $9-12,1989$, Reno, Nevada.

[5] G.L. Bennett, J.J. Lombardo and B.J. Rock, "Developaent and Use of Nuclear Power Sources for Space Applications." Journal of the Astronautical Sciences, Vol. XXXIX, Dec. 1981 .

[6] J.T. Rose, "Conceptual Design of the Mars Rover Sample Return System." AIAA-89-0418, 27 th Aerospace Sclence Meeting, January 9-12, 1989, Reno, Nevada.

[7] J. Randolph, "Mars Rover Sample Return Orbiter Design Concepts." AIAA-89-0421, 27 th Aerospace Sclence Meeting, January $9-12,1989$, Reno, Nevada.

[8] T. Gamberk, L. Rogers, "Aerocapture, Entry and Landing Systems for the Mars Rover Sample Return." AIAA-89-0422, 27th Aerospace Sclence Meeting, January 9-12, 1989 , Reno, Nevada.
[9] D. Pivirotto, T. Penn, W.C. Dias, "Mars Rover 1988 Concepts." AIAA-89-0419, 27th Aerospace Sclence Meeting, January 9-12, 1989, Reno, Nevada.

[10] "Mars Rover, Phase-1 Design Data Book", edited by B.K. Muirhead, Jet Propulsion Laboratory, April 23, 1988.

[11] "Environment of Mars, 1988", Jet Propulsion Laboratory, TM100470, Oct. 1988.

[12] A. Schock, "Design Evolution and Verification of the General Purpose Heat Source." Proceedings of the 1980 Intersociety Energy Conversion Englneering Conference, Volume 2, pages 1032-1042.

[13] G. Bennett, et al, "Update to the Safety Program for the General Purpose Heat Source Radiolsotope Thermoelectr1c Generator for the Gallleo and Ulysses Missions." Iransactions of the Sixth Symposium on Space Nuclear Power Systems, Albuquerque, New Mexico, 8-12 January 1989.

[14] A. Schock, "Modular Isotopic Therwoelectric Generator." Proceedings of the 1981 Intersociety Energy Conversion Engineering Conference, Volume 1 , pages $327-342$.

[15] A. Schock, "Revised MITG Design, Eabrication Procedure, and Performance Predictions." Proceedings of the 1983 Intersociety Energy Conversion Engineering Conference, volume 3 .

\section{ACKNOWLEDGEMENTS}

The above work was supported by the U.S. Department of Energy's Office of Special Applications. 



\title{
THERMAL AND ELECTRICAL ANALYSIS OF MARS ROVER RTGS
}

\author{
A. Schock, T. Or, E. Skrabek \\ Fairchild Space Company, Germantown, MD
}

\section{ABSTRACT}

The RTG designs described in the preceding paper in these proceedings were analyzed for their thersal and electrical performance. Each analysis consisted of coupled therwal. thernoelectric, and electrical analyses, using Fairchild-generated specialized computer codes. These were supplemented with preliminary structural and mass analyses. For each design, various cases representing different operating conditions (water-cooled/radiation-cooled, BOM/EOM, summer/winter, day/night) and different thermoelectric performance assumptions (from conservative to optimistic) were analyzed; and for every case, the heat flow rates, temperatures, and electrlcal performance of each layer of thermoelectric elements and of the overall RTG were deternined. The analyses vere performed in great detail, to obtaln accurate answers permitting meaningful comparisons between different designs. The results presented show the RTG performance achievable with current technology, and the performance improvements that vould be achievable with various technology developments.

\section{INTRODUCTION}

The preceding paper [1] in these proceedings described generic designs of RTGs to power the Mars Rover vehicle of the Mars Rover Sample Return (MRSR) mission under study at JPL. Two specific designs were described: one based on standard unicouples, large assemblies of which have demonstrated stable performance in very lengthy space and ground operations $(>100,000$ hrs): and one based on standard nutticouples. which have demonstrated stability in much shorter tests ( 6000 hrs). The basic design concepts described in that paper are also adaptable to thermoelectric elements containing a variety of geometric and naterials improvements.

The present paper presents mass breakdowns and describes detailed thermal, thermoelectric, and electrical analyses of both 250-watt and 125-watt RTG designs enploying standard unicouples and demonstrated matertals properties . It then proceeds to apply the sane analyses to RTG designs employing thermoelectric elements of postulated advanced geonetries and for materials. Its purpose is to define the RTG parameters achievable with current technology, and to determine how much those paraneters could be enhanced if various itens of new technology could be successfully developed. When this information is coupled with an assessment of the difficulty. cast, and success probability of developing those t tems of new technology, it provides a basis for informed decisions about optimum program strategy for given schedule and budget limits.

\section{MASS BREAKDOWN OF BASELINE RTG}

The "baseline" Mars Rover RTG design is described in the preceding paper [1] and depicted there in Figures 10 and 11 . It contains eighteen General Purpose Heat Source (GPHS) modules and 576 standard unicouples, It is designed for a nominal power output of 250 watts EOM, based on demonstrated thermoelectric performance levels. Its mass breakdown, based on a non-optimized radiator fin design, is presented in the left half of Table 1. The right half of the table shows the corresponding breakdown for the existing Ga7ileo RTG, to ensure that all required RTG components have been properiy accounted for in the Rover RTG mass oreakdowns.

\section{Table 1. Mass of Baseline RTG Versus Galileo RTG}

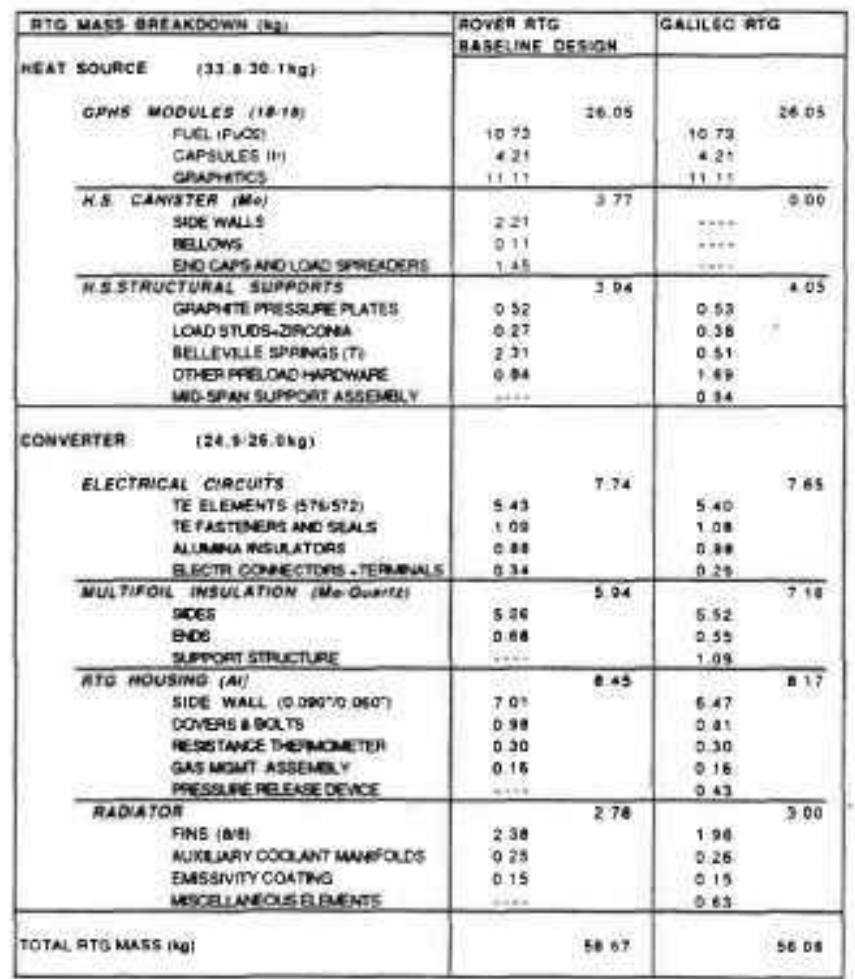


The left colum of Table 1 shows that the baseline RTG has a total mas 5 of $58,7 \mathrm{~kg}$. As shown. most (58\%) of that mass is in the heat source rather than the converter, and most of that ( $77 \%$ ) resides in the heat source modules. It is also noteworthy that the heat source canister, which enables operation of the RTG in the Martian atmosphere, has a mass of $3.8 \mathrm{~kg}$.

The right half of Table 1 shows the corresponding mass breakdown for the existing Ga11teo RTGs. As seen, the baseline Rover RTG, with its non-optimized radiator fins, is $4,6 \%$ heavier than the Galileo RTG. A major part of that difference $(3,77 \mathrm{~kg})$ is due to the canister needed for Mars operations. The other subsystems have very similar nasses in the two RTGs.

\section{MASS OF HALF-LENGTH RTG}

The preceding design assumed that the Rover's 500-watt power requirement would be met by two 250-watt RTGS. For ease of integration, it may prove preferable to employ four 125-watt RTGS, even though these would have a lower efficiency and lower specific power, because of increased end-section heat losses and masses. To assess that option, the reduction in effictency and specific power must be quantified, to support the Rover design trade-off.

Table 2 presents a mass comparison between the two options. For ease of comparison. the table presents masses not for the single RTGs but for the full set of RTGS required to produce 500 watis. The basic design of the half-length RTC is essentially the same as that of the full-iength RTG. The only change, bestdes the $50 \%$ reduction in the number of heat source modules and number of unicouple rings, is a decrease in the wall

Table 2. Mass of "250-W" RTGs Versus "125-W" RTGs

\begin{tabular}{|c|c|c|c|}
\hline ATC MASS HAEAKCOOWA UW & $\begin{array}{l}\text { TWO } 250-W \\
\text { ntgs }\end{array}$ & $\begin{array}{l}\text { Fous } 125 \cdot W \\
\text { atas }\end{array}$ & 2 \\
\hline HEAT SOUACE & & & \\
\hline 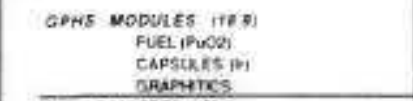 & $\begin{array}{r}210 \\
+47 \\
+228\end{array}$ & $\begin{array}{rl}\begin{aligned} 71 \\
8\end{aligned} & \\
82 & 48 \\
22 & 21\end{array}$ & $\begin{array}{l}0 \\
0 \\
0\end{array}$ \\
\hline H. CANistrat (We) & & & \\
\hline SACE WRUS: & $44 Z$ & 4.4 & 0 \\
\hline Beions & $0 \pi$ & a 49 & $e n$ \\
\hline Dopars ambions smencens & 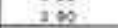 & ats & 1.74 \\
\hline MSSPHUCHUAAL SUPDORTS & & & \\
\hline OWNHTE PPESSUAE PUATES & 104 & 200 & iot \\
\hline Lono snos-zincon & $a=4$ & iog & ost \\
\hline BeLievis spRens ini & $a 2$ & 220 & 242 \\
\hline 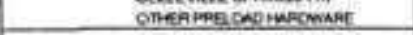 & in & 326 & ies \\
\hline CowVERte & & & \\
\hline ELECTRECAL CIACUITS & & & \\
\hline 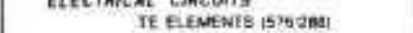 & $10 \mathrm{ng}$ & 1085 & s \\
\hline TE rASTENRS NOSTNS & 210 & 240 & t. 22 \\
\hline ALUELIA WESURATORS & i it & $i>6$ & 000 \\
\hline EufCin ocratcions, +rimews & DGE & $0.8 \mathrm{~B}$ & $\mathrm{D}+2$ \\
\hline 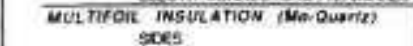 & 1092 & 1052 & . \\
\hline घer & 198 & 272 & ise \\
\hline Afl novinive & & & \\
\hline 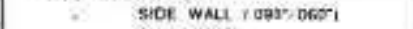 & is $0 \mathrm{eE}$ & $10 \%$ & -200 \\
\hline Bosectar & 0.04 & 1.. $\mathrm{ag}$ & Dos \\
\hline COMEPS: & 196 & 392 & 100 \\
\hline PERSTUCE THEANCWETER & 060 & 170 & $0 \leqslant 0$ \\
\hline gasmont assearer & 028 & 0.54 & +122 \\
\hline Reoutan & & & \\
\hline Fites los: & i 76 & $\Delta 72$ & , \\
\hline 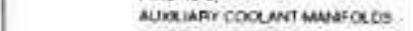 & D 90 & 100 & as \\
\hline Emosstom civernc & 0.00 & 0.0 & A.0 \\
\hline TOTAL UASSCOaI & 17734 & 124 so & 720 \\
\hline
\end{tabular}

thickness of the RTG housing from $0.090^{\circ}$ to $0.060^{\prime \prime}$, and a reduction from three parallel Bellevilie springs to one. These changes from the full-length unit are aade posstble because that the half-iength housing is subjected to lower bending moments under traverse loads, and the half-length heat source stack can be held together with only about one fourth the axial preloao.

Tale 2 shows that the use of four short RTGS instead of two long ones leads to a doubling of the mass of the RTC end sections, including the bellows, graphite pressure plates, load studs, zirconfa insulators, other preload hardware. multifoil end insulation, housing ends and covers, and of the mass of the resistance thermometer, gas management assembly, and auxiliary coolant manifolds. In addition, there is also a significant increase in the mass of the canister end caps and load spreaders and of the radiator fin extenstons. The total mass addition for the short-RTG option add up to $12.3 \mathrm{~kg}$. But these additions are off set by reductions in the mass of the Belleville springs and of the RTG housing side wall totaling $5.1 \mathrm{~kg}$. Thus, the use of four short RTGs leads to a net nass increase of only $7.2 \mathrm{~kg}$ or $6.2 \%$.

\section{MASS DF MULTICOUPLE RTG}

Tables 1 and 2 presented the mass summaries of the unicouple RTGs depicted in Ftgures 10 and 11 of the preceding paper [1]. Table 3 presents the mass sunmary of the multicouple RTG depicted in Figures 13 and 14 , and compares $1 t$ to that of the baseline unicouple RTG.

The two RTGs have the sane EOM power goal, 250 watts per RTG. The unicouples and

Table 3. Mass of Unicouple RTG Versus Multicouple RTG

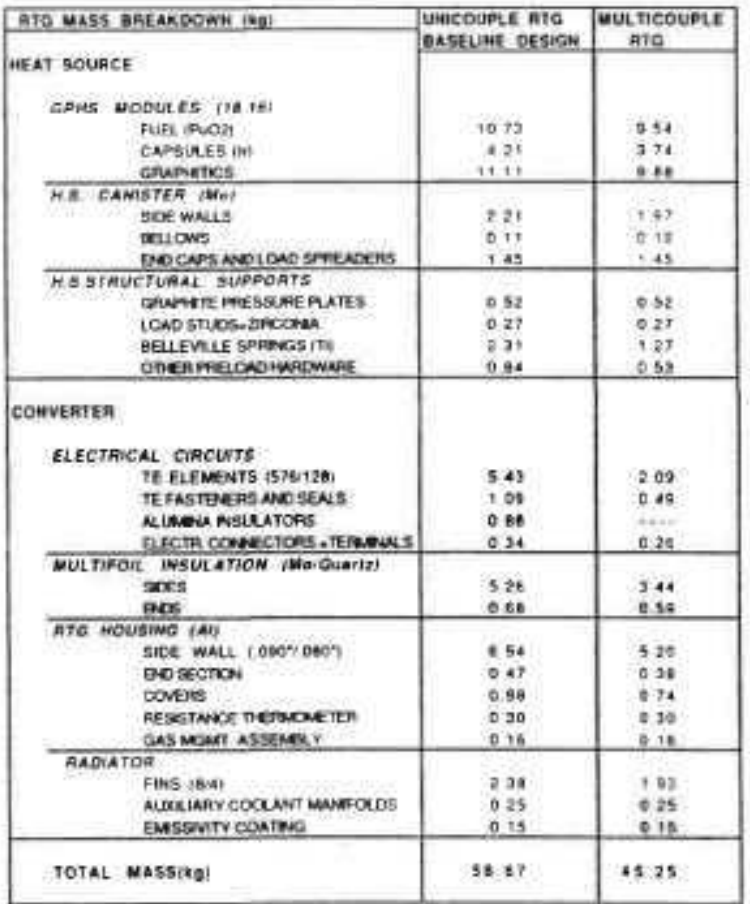


multicouples both use SiGe legs, but the N-legs of the multicouples that were tested contained a Gap additive, which raises the couples: Bom figure of merit (2) from $0.00058 \mathrm{~K}^{-1}$ to 0.00072 $K^{-1}$. This increases the BOM material efficiency from $7.86 \%$ to $8.57 \%$. As a result, the multicouple RTG can achieve its 250-watt output goa) with a lower thermal input power. Therefore, the multicouple RTG design is based on 16 rather than 18 heat source nodules, as indicated in the table.

As shown in Table 3 , the total mass of the multicouple RTG is $23 \%$ lower than that of the baseline RTG $(45.3 \mathrm{~kg}$ versus $58.7 \mathrm{~kg})$. One of the primary causes of that mass reduction is the smalier number of heat source modules and the resuitant shorter RTG length. The shorter length not only has a direct effect on the mass of the RTG housing and the heat source canister, but also results in additional mass savings: the housing wall thickness can be reduced, because the bending moments on the cantilevered structure are lover; and the mass of the Belleville springs is reduced because the axial preload to nold the heat source stack together is lowered.

In addition to the above mass savings, which result from the higher thermoelectric material efficiency, there are also significant savings deriving from the thermal insulation used in the nulticouple RTG. Elimination of the quartz cloth spacers between the 60 layers of Mo fofl results in direct mass savings and in significant indirect savings. The latter occur because the much thinner insulation package and shorter TE legs reduce the RTG housing diameter from $9.1^{*}$ to 7.5". The table reflects the net result of all these mass changes.

Parenthetically, it should be noted that unicouples with Gap-doped $\mathrm{N}$-legs may also be possible. But these have not yet been built and tested, and their development would not be a trivial material substitution because the two types of TE elements employ substantially different hot-junction bonding methods.

\section{RTG THERMAL ENVIRONMENT}

The various RTG destgns kere analyzed for the following four combinations of thermal power and cooling:

1) Beginning-of-Mission (BOM), assumed to be 3 years after fueling, on a hot $\left(300^{\circ} \mathrm{K}\right)$ summer day on Mars, to determine the RTG's maximum notjunction and clad operating temperatures to confirm that they did not exceed established linits.

2) End-of-Mission (EOM), assumed to be 7 years after fueling, on a hot summer day on Mars, to compare the EOM power output with the design goal.

3) EOM on a cold $\left(140^{\circ} \mathrm{K}\right)$ winter night on Mars, to deternine the effect of a cold environment on EOM power.

4) BOM with the RTG contained within the Rover's aeroshell and with its fins cooled by an auxiliary coolant 10op, to determine the power output and RTG temperatures during transit to Mars. (The auxiliary cooling tubes were tentatively assumed to have a wall temperature of $\left.100^{\circ} \mathrm{C}\right)$.

A11 the design analyses completed to date were based on the unrealistic assumption that each RTG has an unobstructed vier of space and of the Martian ground. In addition, we plan to anatyze the case of four 125-RTGs mounted in parallel on top of the Rover, at its four corners, to assess the effect of mutual blockage of theif radiators. This is a concept currently favored by some Rover designers at JPL.

\section{THERMAL AND ELECTRICAL ANALYSIS}

The analysis described in this section consists of three parts (thermal. thermoelectric. and electrical), which must be performed simultaneously and interactively. The analysis uses specialized computer codes generated by Fairchild to compute the heat flows, temperatures, and electrical parameters of each Tayer of thermoelectric elenents. Inputs include the RTG design, the thermal input power (BOM/EOM), the cooling mode (water/radiation, Mars environment), the TE materials and performance, and the desired electrical output voltage.

The thermal analysis employs a 425 -node SINDA model of the axisymmetric RTG to compute the axial variation of the temperatures of the various RTG components. That axial variation is appreciable, because of unavoidable end losses through the structural supports at the top and botton of the heat source stack. Each heat source module and thermoelectric element layer is discretely represented in the SINDA model.

The computed heat flow through the various TE elements includes the effects of Peltier cooling: ohmic heating in legs, electrodes, and leads; heat converted to electricity (i.e., the TE legs effectively act as heat sinks); and heat losses through multifoil, glass, and quartz yarn wrap.

The thermoelectric analysis includes the effects of measured contact resistances and ohmic losses in legs, electrodes, and leads: experimentaliy determined effects of long-tern material degradation of SiGe; and optimized $\mathrm{n} / \mathrm{p}$ leg area ratios. Other constraints are that all $T E$ elements in series must have the sane current, and $a 11$ in parallel must have the same voltage.

The analysis uses temperature-dependent values of the Seebeck coefficient, electrical resistivity, and thermal conductivity for the sice $N$ and $P$ legs, wth a temperature-averaged figure of merit (Z) of $0.000583 \mathrm{~K}^{-1}$ at $\mathrm{BOM}$ and $0.000548 \mathrm{~K}^{-1}$ at EOM for the baseline SiGe unicouple. The thermal and electrical results are used to compute the material efficiency, couple efficiency, and converter efficiency of each layer of TE elements, and the overall RTG system efficiency.

The thermal analysis of the initial design assumed an RTG housing wall thickness of $0.090^{*}$ 
and eight radtator fins of a trapezoidal crosssection, with a fin root thickness of $0.060^{\prime \prime}$, a fin tip thickness of $0.015^{\prime \prime}$, and a root-to-tip fin height of $3.0 \%$. The fins have an axial length of $42.7^{\prime \prime}$. Thus, they extend $2.5^{\circ}$ beyand each end of the active thermoelectric zone. These dimenstions were based on the results of a preliminary structural analyses described in the next paper at this conference [2].

\section{TEMPERATUAE OISTRIBUTION OF BASELINE RTG}

Figure 1 shaws the BOM temperature distribution (in ${ }^{\circ}$ ) of the radiation-cooled baseline RTC for a $300^{\circ} \mathrm{K}$ sink temperature. It shows the temperatures of the RTG end regions. and the temperatures at the center of the RTG. The temperatures shown are for an RTG with unicouples of standard dimensions, except that the cross-sectional areas of their sige legs have been reduced by $9 \%$ from the corresponding values in the Galfleo RTG. This was done in order to take full advantage of the unicouples' maximum temperature capability.

Figure 1. BOM Temperature Distribution $\left({ }^{\circ} \mathrm{C}\right)$ in Baseline RTG

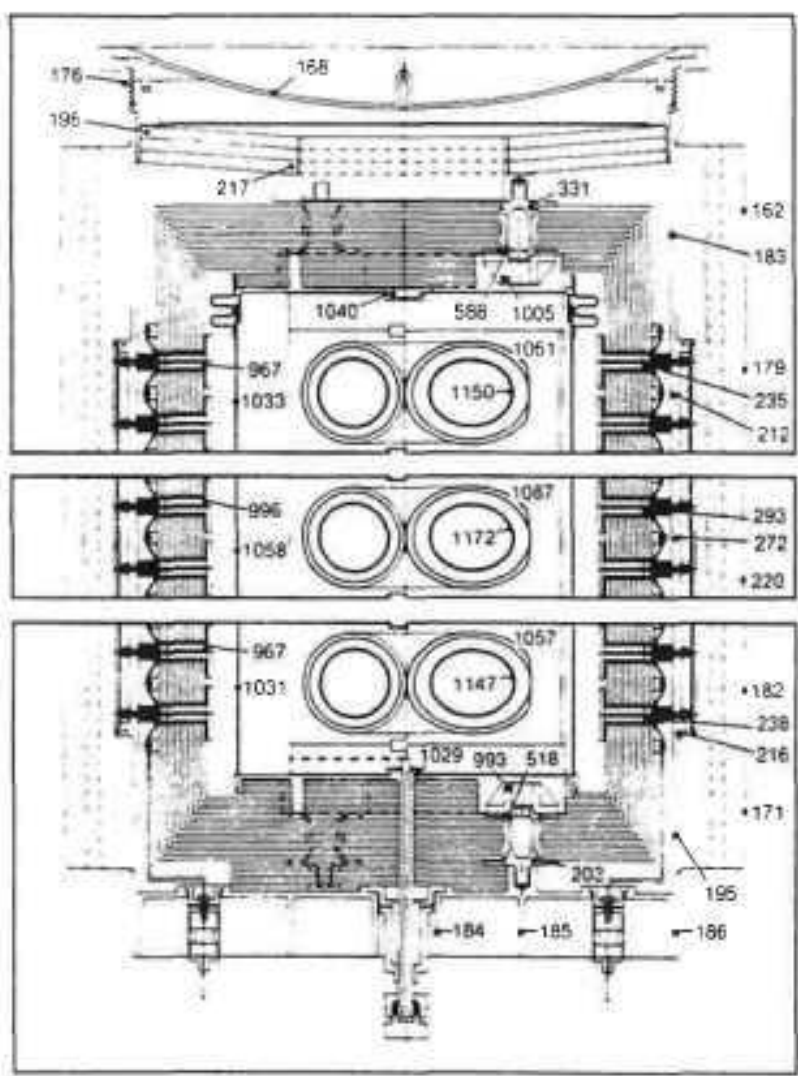

The figure shows the maximun temperatures of the iridium $\left(1172^{\circ} \mathrm{C}\right)$, the graphite heat source surface $\left(1087^{\circ} \mathrm{C}\right)$ the molybdenum canister $\left(1058^{\circ} \mathrm{C}\right)$, the sice hot junction $\left(996^{\circ} \mathrm{C}\right)$ and cold junction $\left(293^{\circ} \mathrm{C}\right)$. of particular interest are the maxisum temperatures of the zirconia insulators $\left(1 \cos ^{\circ} \mathrm{C}\right)$, the Inconel support studs $\left(598^{\circ} \mathrm{C}\right)$, the titanium springs $\left(217^{\circ} \mathrm{C}\right)$, and the aluninum housing $\left(272^{\circ} \mathrm{C}\right)$. since their mechanical properties and creep characteristics are strang functions of temperature.

To fllustrate the approach used in the thermal, thernoelectric, and electrical analyses of the various RTG designs, the BOM results for the baseline RTG radiating to a $300^{\circ} \mathrm{K}$ sink are presented in detail in Figures 2,3 , and 4 . (Similar detailed results were generated for each design option and each environment investigated.)

\section{AXIAL VARIATION OF HEAT FLOW RATES}

The BOM temperatures shown in Figure 1 result in the axial variation of heat flow rates to and from each ring of thermoelectric unicouples and their associated converter sections shown in Figure 2 .

Figure 2. Axial Variation of Heat Flow Rates

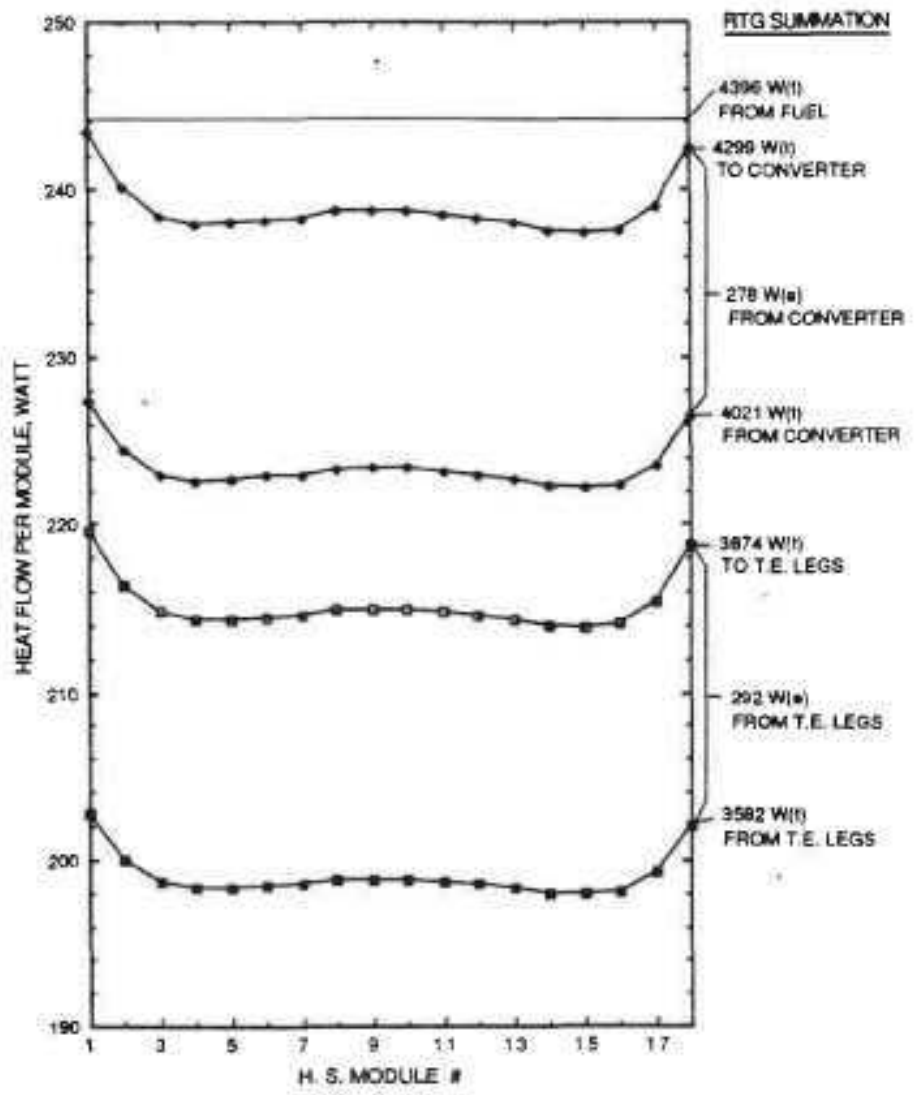

The numbers at the right edge of the figure show the summed neat flows for the whole RTG. AS can be seen, this RTG design has a thermal efficiency of $3874 / 4396=89 \%$. The 97-watt difference between the 4396 watts generated by the fuel and the 4299 watts flowing to the converter represents the axtal heat loss from the ends of the heat source stack; and the 425-watt difference between the heat flow to the converter and the 3874 watts flowing to the TE legs represents the heat losses through the thermal insulation and quartz yarn wrap surrounding the TE elements. 
The 292-watt difference between the heat flows to and from the TE legs (curves 4 and 5 ) represents the gross electrical power output: and the 278-watt difference between the heat flows to and from the converter (curves 2 and 3 ) represents the net electrical power output, ofter lead losses.

\section{AXIAL TEMPERATURE PROFILES}

Figure 3 depicts the axial tenperature variations in the RTG. The heat losses from the end of the heat source stack result in the depicted temperature profiles of the fuel capsule clads, the modules' aeroshell surfaces, the canister, and the unicouple hot junctions. The figure also shows the axial temperature variations of the cold junctions, the fin root. and the fin tip.

Figure 3. Axial Temperature Profiles

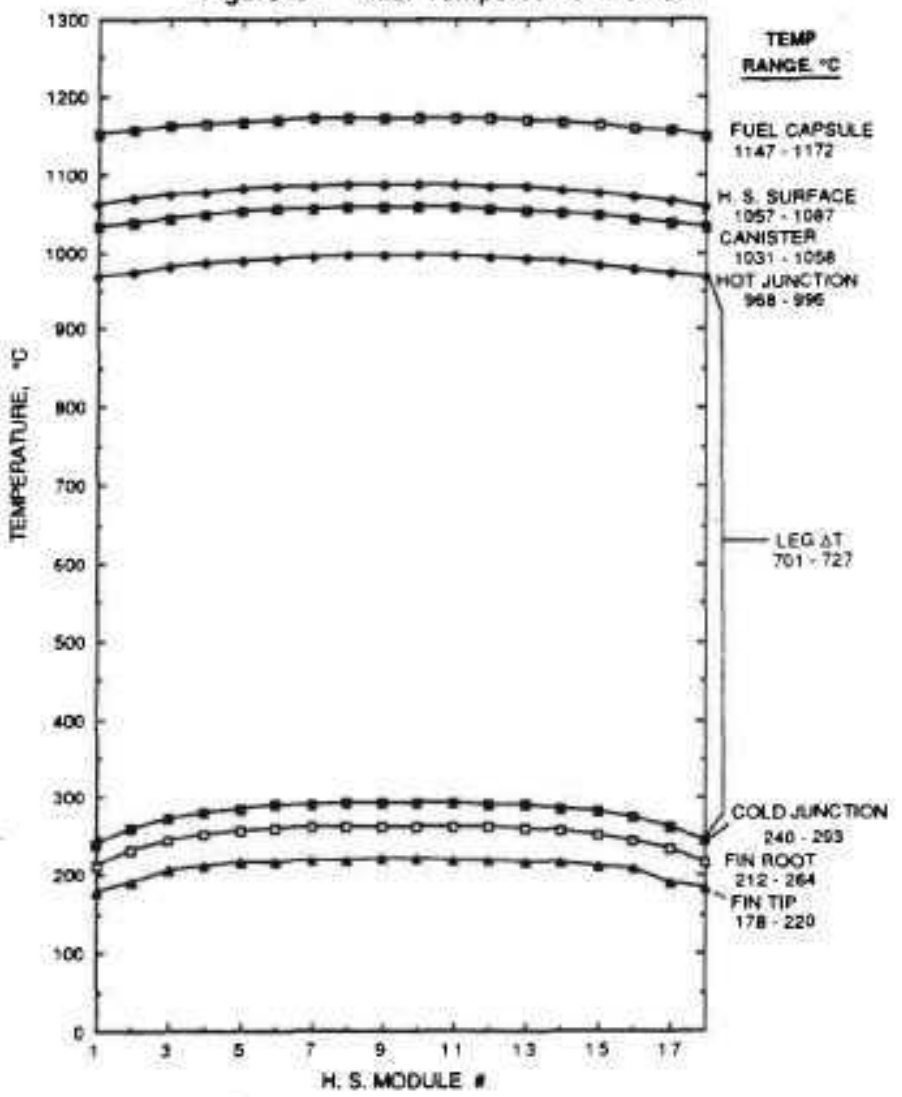

The figure shows six temperature drops between the various curves. The first $\left(-85^{\circ} \mathrm{C}\right)$ represents the drops inside the heat source madules, across the graphitics and helium gaps. The second $\left(-29^{\circ} \mathrm{C}\right)$ is the drop across the helium gap to the canister, and the third $\left(-62^{\circ} \mathrm{C}\right)$ is across the vacuum gaps and through the TE heat collectors. The fourth $\left(703\right.$ to $\left.728^{\circ} \mathrm{C}\right)$ is the temperature drop across the $516 e$ TE legs. As can be seen, this is the largest of the drops. It is the only one that makes a useful contribution in actually generating electrical power. All the other temperature drops represent thermodynamic losses. The fifth drop $(-290 \mathrm{C})$ represents the thernal resistance of the unicouple's cold-end and the loss for circunferential heat transport through the aluminum housing to the nearest fin; and the sixth drop $\left(44^{\circ} \mathrm{C}\right)$ is that due to radial heat flow through the fin itself.

The depicted variation of the hot-junction temperatures would result in a significant performance loss, were it not balanced by a similar convex profile of the cold-junction temperatures. This was achieved by extending the radiator fins beyond the active length of the RTG, as mentioned earlier. In fact, the temperature drop-off of the cold junctions near the RTG ends is greater than that of the hot junctions. This explains why the unicouples' heat flow rates, power outputs, and efficiencies are actually higher at the ends of the RTG than at the center, as shown in Figures 2 and 4 .

\section{AXIAL VOLTAGE AND EFFICIENCY PROFILES}

The temperature varfations shown in Figure 3 result in the unicouple voltage and efficiency profiles displayed in Figure 4 . The averaged values for the RTG are shown at the right edge of the figure. The 0.010 -voit difference between the gross and net couple voltages represents the electrical losses in the leads.

Figure 4. Axial Voltage and Etficiency Profiles

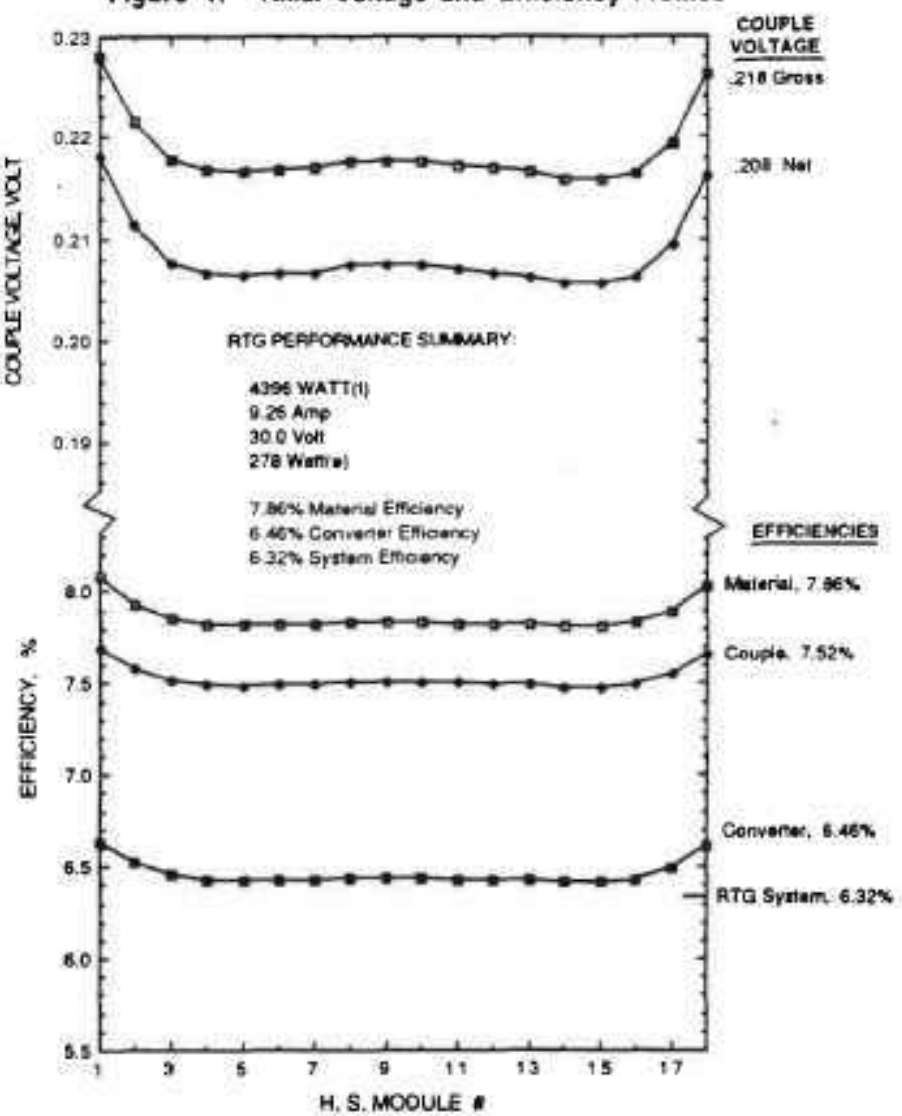

The difference between the $7.86 \%$ material efficiency and the $7.52 \%$ couple efficiency is the effect of ohmic losses in the electrodes. The difference between the couple efficiency and the $6.46 \%$ converter efficiency shown in the figure reflects the electrical losses in the leads and the thermal losses through the multifoil side 
Insulation and the quartz yarn wrap. As seen. the axial variation of the efficiencies is quite small. In fact, the couples near the ends have a higher efficiency because of their lower coldjunction temperatures. Which result from axially extending the radiator fins beyond the thermoeiectric region. The 0.55 -percentage-point difference between the overall converter efficiency and the 6.32\% systen efficiency reflects the heat losses through the RTG ends.

Figure 4 shows that there are substantfal differences between the BOM material efficiency. couple efficiency. converter efficiency. and system efficiency. This highilghts the importance of specificity in reporting RTG efficiencies.

\section{EFFECT OF COOLING MODE ON RTG PERFORMANCE}

Tabie 4 illustrates the effect of the cooling mode on the BOM temperature distribution. efficiencies, and output of the baseline RTG. The left column shows the results for the watercooled RTG, representative of the launch and orbita? transit conditions: the middle column present the corresponding results for the radiation-cooled RTG. representative of operations on a Martian sumner day $\left(300^{\circ} \mathrm{K}\right)$; and the right column shows similar results for a Martian winter night $\left(140^{\circ} \mathrm{K}\right)$.

Table 4. Effect of Cooling Mode on BOM Pertormance of Baseline RTG

\begin{tabular}{|c|c|c|c|}
\hline \multirow{3}{*}{$\begin{array}{l}\text { Cooling Mode } \\
\text { Auxtiary Coolant Wall Temp. "C } \\
\text { Aadiatoe Sink Temperature. } \mathrm{K} \text {. }\end{array}$} & \multirow{3}{*}{$\begin{array}{c}\text { Conveclive } \\
100 \\
300\end{array}$} & \multicolumn{2}{|c|}{ Radiative } \\
\hline & & - & - \\
\hline & & 300 & 140 \\
\hline \multicolumn{4}{|l|}{ Maximum Temperature ${ }^{\circ} \mathrm{C}$} \\
\hline Fuel Clad & $10 \not 9$ & 1172 & 1166. \\
\hline HS Surtace & 992 & 2087 & 1080 \\
\hline Canisief & 957 & 1058 & 3051 \\
\hline TE Hot Junction & 888 & 996 & 988 \\
\hline TE Cold Junction & 155 & 293 & 264 \\
\hline Fin ROO: & 117 & 264 & 254 \\
\hline Fin Tip & 94 & 220 & 210 \\
\hline \multicolumn{4}{|l|}{ Elticiency " } \\
\hline Materiai & 797 & 786 & 788 \\
\hline Couple: & 751 & 752 & $7 \$ 3$ \\
\hline Converter: & 550 & -6.46 & 648 \\
\hline Syslem & 6.37 & 6.32 & E. 32 \\
\hline \multicolumn{4}{|l|}{ ATG Output: } \\
\hline Current amp & 9.26 & 9.26 & 9.26 \\
\hline Vollage & 30.2 & 300 & 30.1 \\
\hline Power & 280 & 278 & 278 \\
\hline Specilic Power, watt/kg & 4.77 & 4.74 & 4.74 \\
\hline
\end{tabular}

The left and infdde fin root temperatures are used to compute the differential thermal expansion of the aluminum housing, which dictates the required Belleville spring travel of $0.099^{*}$, This thermal expansion difference results in a relaxation of the axial spring load. Consequently, the lateral G-loads that the heat source stack can tolerate are $40 \%$ lower on Mars than during launch.

Comparison of the three sets of efficiencies and RTG outputs show almost identical results for the three cases. This is because. for a fixed design. changes in the cold-junction temperatures cause similar changes in the not-junction temperatures: and because the temperatureintegrated thermoelectric properties of sige are not very sensitive to cold-junction temperature. As a result, the power output of the RTG is quite insensitive to thermal envisonnent. so that the RTG can produce essentially the same power during launch and during transit to Mars as that generated on Mars in either summer or winter. We therefore conclude that the RTG can deliver full operating power during the water-cooled cruise to Mars: and that the power output of the radiatively cooled RTG is essentialiy independent of the Martian temperature.

\section{EFFECT OF LIFETIME ON RTG PERFORMANCE}

Table 5 illustrates the change from BOM $\{3$ years after fuel encapsulation) to EOM ( 7 years after fuel encapsulation) on the output of the radiation-cooled baseline RTG with a $300^{\circ} \mathrm{K}$ sink temperature. The left colunn oisplays the BOM temperatures and output voltage, current. power, and efficiencies of the RTG, and the right half shows the corresponding EOM values.

Table 5. Effect of Mission Time on Performance of Baseline RTG

\begin{tabular}{|c|c|c|}
\hline Mission Time & BOM & EOM \\
\hline Years Atter Fuel Encapsulation & 3 & 7 \\
\hline Years of Fult-Temperature TE Operation & 1 & 5 \\
\hline Thermal Power watts & 4396 & 4261 \\
\hline \multicolumn{3}{|l|}{ Maximum Temperature. 'C: } \\
\hline Fuel Clad & $\$ 172$. & 1152 \\
\hline H.S. Surface & 3087 & 1065 \\
\hline Canister & 1058 & 1037 \\
\hline TE hat Junction & 996 & 975 \\
\hline TE Cold Juncsion & 253 & 289 \\
\hline Fin Foot & 286 & 260 \\
\hline Fin Tip & 220 & $21 \mathrm{a}$ \\
\hline \multicolumn{3}{|l|}{ Efliciency, $5 / 2$} \\
\hline Matetial & 7.86 & 7.41 \\
\hline Couple & 7.52 & 7.12 \\
\hline Convener & 646 & 6,13 \\
\hline System & 6.32 & 6.01 \\
\hline \multicolumn{3}{|l|}{ RTG Output: } \\
\hline Current, amp & 926 & 8.52 \\
\hline Voltage & 300 & 300 \\
\hline Power. watt & $27 t$ & 256 \\
\hline Specitic Power, wattikg & 474 & 4.37 \\
\hline
\end{tabular}

The biggest cause of pover output change during that period is the decay of the radioisotope fuel. which has a half-life of approximately 89 years. As a result, the original 4500-watt thermal power of the 18-module heat source drops to 4396 watts at BOM and to 4261 watts at EOM. As shown in Table 5, this lowers the maximum clad temperature from $1172^{\circ} \mathrm{C}$ to $1152^{\circ} \mathrm{C}$, drops the naximum hot-junction tenperature from $996^{\circ}$ to $975^{\circ} \mathrm{C}$, and reduces the maximua temperature drop in the StGe legs from $703^{\circ} \mathrm{C}$ to $686^{\circ} \mathrm{C}$.

This temperature drop reduction lowers the conversion efficiency. The reduced thermal power and reduced efficiency combine to cause a greater-than-proportional reduction in power output. This would be true even if there vere no concurrent degradation in thermoelectric 
properties of the SiGe. But there is a wellcharacterized material degradation, primarily because of dopant precipitation. As a result, the systen effictency actually drops from $6.32 \%$ to 6.01\% and the power output drops from 278 watts to 256 watts, as shown in the table. We therefore conclude that the combined effect of fuel decay and thermoelectric degradation is to reduce the power output by $-8 \%$.

Table 5 shows that the power output of the baseline RTG exceeds the goal of 250 watts EOM. Without exceeding the $1000^{\circ} \mathrm{C}$ hot-junction temperature 1 imit or the $1330^{\circ} \mathrm{C}$ clad 1 imit.

\section{EFFECT OF RTG LENGTH ON PERFORMANCE}

The nasses of the two "250-watt" RTGS were compared with those of four "125-watt" RTGS in Tabie 3. The temperatures, efficiencies, and outputs for the two options are compared in Table 6. both for $B O M$ and $E O M$.

Table 6. Effect of RTG Length on Performance

\begin{tabular}{|c|c|c|c|c|}
\hline 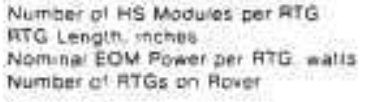 & & & & 25 \\
\hline Nission Time & $\operatorname{sen}$ & EOM & SOM & EON \\
\hline TAemai Power pa: RTO wall. & 4396 & 4281 & 2198 & 2131 \\
\hline 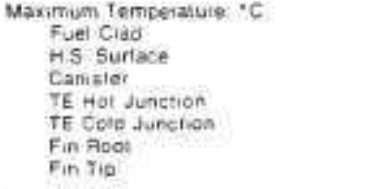 & $\begin{array}{l}1772 \\
1067 \\
1058 \\
995 \\
293 \\
264 \\
220\end{array}$ & $\begin{array}{l}1152 \\
1065 \\
10077 \\
675 \\
269 \\
260 \\
218\end{array}$ & $\begin{array}{l}1172 \\
1056 \\
1059 \\
966 \\
275 \\
247 \\
206\end{array}$ & $\begin{array}{l}1159 \\
1067 \\
1039 \\
980 \\
271 \\
245 \\
205\end{array}$ \\
\hline $\begin{array}{l}\text { Etheiency: Pe: } \\
\text { Material } \\
\text { Couble } \\
\text { Converner: } \\
\text { Sysiem }\end{array}$ & $\begin{array}{l}7.86 \\
7.52 \\
6.46 \\
6.32\end{array}$ & $\begin{array}{l}7.41 \\
2.12 \\
613 \\
601\end{array}$ & $\begin{array}{l}8.07 \\
7.72 \\
6.51 \\
5.32\end{array}$ & $\begin{array}{l}7.58 \\
729 \\
626 \\
596\end{array}$ \\
\hline $\begin{array}{l}\text { Outpus at Set of RTGs } \\
\text { Cutrent, amp } \\
\text { Voltage } \\
\text { Fower watl }\end{array}$ & $\begin{array}{l}785 \\
300 \\
566\end{array}$ & $\begin{array}{l}170 \\
300 \\
512\end{array}$ & $\begin{array}{l}183 \\
302 \\
556\end{array}$ & $\begin{array}{l}783 \\
302 \\
508\end{array}$ \\
\hline $\begin{array}{l}\text { Mass of Set of RTGs ki } \\
\text { Specific Rower, watikg }\end{array}$ & $\begin{array}{l}1173 \\
674\end{array}$ & $\begin{array}{l}1173 \\
437\end{array}$ & $\begin{array}{l}124 E \\
446 .\end{array}$ & $\begin{aligned} 12 e .6 \\
4.0 B\end{aligned}$ \\
\hline
\end{tabular}

The table shows that the short RTGS also meet their design goal (125 watt EOM per RTG) without exceeding the $1000^{\circ} \mathrm{C}$ hot-junction temperature iimit. It shows that the system efficiency of the short RTG is almost as high as that of the long RTG.

This was not expected, because the four short RTGs have twice as many end sections and obviously have greater heat losses from the ends of their heat source stacks. Evidently, these losses are compensated by their higher converter efficiencies, as shown in the table. Their higher converter efficiency is due to their lower coid-junction temperature $\left(271^{\circ} \mathrm{C}\right.$ versus $\left.289^{\circ} \mathrm{C}\right)$ which results from the greater effectiveness of the axial radiator extensions in the short RTGs. It should be noted, however, that the radiator fin design has not yet been optimized for either the long or the short RTGs.

Table 6 shows that the specific power of the short RTG is $9 \%$ lower than that of the long ones. This is primarily due to their higher mass rather than lower system efficiency. The difference in specific power between the two options is small enough to make the short RTG option a viable alternative to the baseline design, if the shorter units are indeed easier to integrate with the Rover (e.g., because the shorter RTGs are less prone to block the Rover's sensors and/or antennas). But this conclusion will have to be re-exainined after the effect of mutual radiator blockage of nultiple RTGs is taken into account.

An additional advantage of the short RTGs is that if one of the four should expertence catastrophic fallure before the end of the mission, the ather three would still supply $75 \%$ of the Rover's design power, permitting continued Mars operations on a limited scale.

\section{MULTICOUPLE RTG PERFORMANCE}

The preceding paper [1] described basic designs for RTGs employing standard unicouples (UC) and standard multicouples (MC). The multicouple RTG design shown in Figures 13 and 14. with demonstrated MC performance parameters. was subjected to detailed thermal, thermoelectric. and electrical analyses. identical to those performed for the baseline (unicouple) RTG.

The results of those analyses for the two RTGs are summarized in Table 7, which compares their temperatures. efficiencies, output powers. and specific powers. Both cases are for

Table 7. Performance of Multicouple RTG Versus Unicouple RTG

\begin{tabular}{|c|c|c|c|c|}
\hline Thermoelectric Elements & \multicolumn{2}{|c|}{ Unicouples : } & \multicolumn{2}{|c|}{ Multicouples } \\
\hline $\begin{array}{l}\text { Number of Elements } \\
\text { Number of H.S. Modules }\end{array}$ & \multicolumn{2}{|c|}{$\begin{array}{l}576 \\
18\end{array}$} & \multicolumn{2}{|c|}{$\begin{array}{l}128 \\
16\end{array}$} \\
\hline $\begin{array}{l}\text { RTG Length, inches } \\
\text { RTG Housing Diameler, inches }\end{array}$ & \multicolumn{2}{|c|}{$\begin{array}{l}45.9 \\
9.1\end{array}$} & \multicolumn{2}{|c|}{$\begin{array}{l}41.6 \\
7.5\end{array}$} \\
\hline $\begin{array}{l}\text { N-Leg Material } \\
\text { Couple Figure of Merit, K-1 }\end{array}$ & \multicolumn{2}{|c|}{$\begin{array}{l}\mathrm{sige} \\
0.00058\end{array}$} & \multicolumn{2}{|c|}{$\begin{array}{l}\text { SiGelGaP } \\
0.00072\end{array}$} \\
\hline $\begin{array}{l}\text { Number of Fins } \\
\text { Fin Root Thickness, inch } \\
\text { Fin Length, inches }\end{array}$ & \multicolumn{2}{|c|}{$\begin{array}{c}8 \\
0.060 \\
3.0\end{array}$} & \multicolumn{2}{|c|}{$\begin{array}{c}4 \\
0.100 \\
5.5\end{array}$} \\
\hline $\begin{array}{l}\text { Mission Time } \\
\text { Thermal Power per ATQ, watt }\end{array}$ & $\begin{array}{l}8 O M \\
4396\end{array}$ & $\begin{array}{l}\text { EOM } \\
4261\end{array}$ & $\begin{array}{l}\text { BOM } \\
3907\end{array}$ & $\begin{array}{l}\text { EOM } \\
3787 \\
\end{array}$ \\
\hline \multicolumn{5}{|l|}{ Maximum Temperature. " $\mathrm{C}$. } \\
\hline Fuel Clad & 1172 & 1152 & 1171 & 1154 \\
\hline H.S. Surtace & 1087 & 1065 & 1085 & 1068 \\
\hline Canister & 1058 & 1037 & 1057 & 1040 \\
\hline TE Hot Junetion & 996 & 975 & 1009 & 991 \\
\hline TE Cold Junction & 293 & 289 & 315 & 309 \\
\hline Fin Root & 264 & 260 & 259 & 255 \\
\hline Fin Tip & 220 & 218 & 184 & 182 \\
\hline \multicolumn{5}{|l|}{ Etriciency, $\%$ : } \\
\hline Material & 7.86 & 7.41 & 8.57 & 8.14 \\
\hline Couple & 7.52 & $7: 12$ & 8.01 & 7.60 \\
\hline Converter & 6.45 & 6.13 & 7.05 & 6.68 \\
\hline System & 6.32 & 6.01 & 6.76 & 6.42 \\
\hline \multicolumn{5}{|l|}{ RTG Output: } \\
\hline Current, amp & 9.3 & 8.5 & 9.0 & 8.3 \\
\hline Voltage & 30.0 & 300 & 29.5 & 29.5 \\
\hline Power, watt & 278 & 256 & 264 & 243 \\
\hline $\begin{array}{l}\text { ATG Mass, } \mathrm{kg} \\
\text { Specitic Power, wattikg }\end{array}$ & 58.6 & $\begin{array}{l}58.6 \\
4.37\end{array}$ & 45.3 & 45.3 \\
\hline Specitic Power, wattikg & 4.74 & 4.37 & 5.83 & 5.37 \\
\hline
\end{tabular}


radiation cooling with a $300^{\circ} \mathrm{K}$ heat sink. The unicouples employed SiGe $n-$ and $p$-legs, with a BOM figure of merit (Z) of 0.00058 . In the case of the multicouples, the n-legs contain a GaP additive, which raises the $80 \mathrm{M} Z$ to 0.00072 . Both cases employed measured values of contact resistances for their respective TE elements. Because of its higher $z$ and anticipated higher efficiency, the multicouple RTG used 16 instead of 18 heat source modules.

Table 7 shows very similar temperatures for the RTGs, with two exceptions. The first is that the temperature drop from the cold junction to the fin root is much higher $\left(56^{\circ} \mathrm{C}\right)$ in the multicouple-RTG than in the unicouple-RTG $\left(29^{\circ} \mathrm{C}\right)$. This is due to the fact that each multicouple rejects much more heat than a unicouple, and that this heat has to flow through a greater distance to reach the nearest fins, sfnce the MC-RTG has only four fins instead of eight.

The second difference between the tro RTGs is that the root-to-t ip temperature drop in the fins is appreciable greater $\left(75^{\circ} \mathrm{C}\right)$ in the MC RTO than in the UC unit $\left(44^{\circ} \mathrm{C}\right)$. This is due to the fins greater length, wich is necessitated by the smaller number of fins.

In spite of these increased temperature drops, the MC RTG shows virtually the same system efficiency the UC RTG. This is due to the use of the GaP additive in the $n$-legs, which raises the figure of merit from $0.00058 \mathrm{~K}^{-1}$ to $0.00072 \mathrm{~K}^{-1}$ and the $80 M$ material efficiency from $7.86 \%$ to 8.57\%. As shown in Table 7, the MC RTG with 16 heat source modules produces $5 \%$ less power than the UC RTG with 18 heat source modules. In ract, it falls a little below its 250-watt EOM goal.

The last two lines of Table 7 compare the masses (from Table 3 ) and the specific powers of the two RTGs. As can be seen, the speciftic power of the MC RTC is $23 x$ higher than that of the UC RTG. This benefit must be weighed against their lower technological maturity and higher programmatic risk.

\section{EFFECT OF THERMOELECTRIC MATERIAL PROPERTIES}

Materials Studied: The results thus far were a 11 based on demonstrated thermoelectric properties of the siGe unicouples and the SiGe/Gap multicouples. The present section exanines the effect which improvements of those properties would have on the RTG designs and on their mass and performance. RTGS based on five different material modeis were analyzed:

1. The first is a JPL model for SiGe, with 78\% Si in the hotter $85 \%$ of the TE legs and $63 \%$ Si in the coaler $15 \%$ of the leg. This is the same material model used in our baseline design analysis, and is representative of the unicouples used in the Galileo RTGs. At BOM, it yteids a figure of merit of $0.000584 \mathrm{k}^{-1}$ over a $1000^{\circ} \mathrm{C}-$ to $-300^{\circ} \mathrm{C}$ temperature range.
2. The second material model employed is designated ITM-197. The material's thermoelectric properties have been confirmed by measurements at independent laboratories, but it has not yet been built into a couple. Its BOM figure of mertt is $0.000768 \mathrm{~K}^{-1}$.

3. The third material model, designated GE Hybrid, represents the materials used in the multicouples built and tested to date. It was used as the basis for our multicouple design. Its BOM figure of eerit (2) is $0.000782 \mathrm{~K}^{-1}$. It has not yet been built into unicouples. Doing so would require development of new bonding techniques.

4. The fourth material model, designated SP-100, represents the thermoelectric performance paraneters assumed for the SP-100 reactor system reference design. It assumes a GaP-doped $n$-leg $(z=0,00111)$ and a siGe $p$-ieg with an as-yet undefined additive $(Z=0,00069)$, yielding a couple 2 of $0.00085 \mathrm{~K}^{-1}$. This performance level has not yet been achieved.

5. The fifth material mode1 is designated "dream". Its composition and development pathway are not known to the authors. It was included at JPL's request, to quantify what effect a figure of merit of $0.00140 \mathrm{~K}^{-1}$ would have on RTG performance, if such a matertal could be successfully developed.

Assumptions: The five RTG designs were based on the sane basic arrangenent, 1.e., the baseline design employing 16 unicouples (of $0.8^{\prime \prime}$ leg length) per horizontal ring, connected four in parallel. However, the number of heat source modules, the number of unicouples, and the crosssectional areas of the unicouple legs were varied to meet (or come close to) the RTG voltage and power goals. The voltage goal used was 30 volts after lead losses: and the power goal was - $250 \mathrm{~W}$ EOM or $280 \mathrm{w} B O M$ after lead losses. Each of the five material models enployed temperaturedependent resistivities, conductivities, and Seebeck coefficients for the $n$ - and p-legs.

The primary emphasis in the design studies and analyses was to determine the relative PTG performance for the five options, rather than their absolute values. For this reason, and in the interest of expediency, a number of approximating assumptions were made:

The axfal variations of the heat flow rates, temperatures, and couple outputs were ignored. A11 couples were assumed to operate at the same hot-junction temperature $\left(1000^{\circ} \mathrm{C}\right)$ and coldjunction temperature $\left(300^{\circ} \mathrm{C}\right)$ employed in previous RTG tests. In addition, the fraction of the generated heat that flows to the thermoelectric couples was assumed to be $88 \%$, based on the results of the more detailed and exact analysis of the baseline RTG design.

Based on the same analysis, the effect of the electrode resistances and the electrical contact resistance were accounted for by increasing the materials' resistivities by $10 \%$; and the effect of electrical lead losses was accounted for by subtracting $6 \%$ from each couple's output voltage. 
Finally, the number of thermoelectric rings per heat source module had been arbitrarily fixed at 2.0 in the baseline design (for consistency with the Galileo RTG), but was varied in each of the five comparison designs so as to maxinize the conversion effictency.

Because of these differences in analyticai approach, the results of the material comparison analysis are not an exact match to those of the baseline RTG analysis, But the conparison analysis is internally consistent, and its results are a valid comparison of the relative RTG performance for the five TE materials.

Thermoelectric Analysis: The critical material properties of a thermoelectric couple are the temperature-dependent Seebeck coefficient $S^{\prime}$, thernal conductivity $k^{\prime}$, and electrical resistivity $\rho^{\prime}$ of its $n$ - and $p$-legs. The first step in the analysis is to use these to compute the temperature-averaged values:

$$
\begin{aligned}
& S=\int_{\pi_{r}}^{n_{n}}\left(S_{n}^{\prime}+S_{p}^{\prime}\right) d T / \Delta T . \\
& k_{n}=\int_{r_{r}}^{T_{k}} k_{n}^{\prime} d T / \Delta T . \\
& k_{p}=\int_{T_{p}}^{\eta_{n}} k_{p}^{\prime} d T / \Delta T . \\
& \rho_{n}=\int_{T_{r}}^{r_{p}} \beta k_{n}^{\prime} \rho_{n}^{\prime} d T / k_{n} \Delta T \text {, and } \\
& \rho_{p}=\int_{t_{r}}^{T_{n}} \beta k_{p} \rho_{p}^{\prime} d T / k_{p} \Delta T .
\end{aligned}
$$

where $T_{h}$ and $T_{c}$ are the assuned hot- and coldjunction temperatures, $\Delta T$ is the difference between them, and the factor $\beta$ accounts for the resistances of the contacts and the electrodes. Based on the detalled analysis of the baseline RTG, a value of 1.10 was used for $\beta$.

A thermoelectric couple with $n$ - and $p$-legs of length $L$ and combined cross-sectional area $A$ has a thermal conductance

$$
K=\left[k_{n} \alpha+k_{p}(1-\alpha)\right](A / L)
$$

and an electrical resistance

$$
R=\left[\rho_{n} / \alpha+\rho_{p} /(1-\alpha)\right](L / A),
$$

where $\alpha$ is the area fraction of the $n-1 e g$ and $1-\alpha$ is the area fraction of the $p-1 \mathrm{eg}$. If the couple operates at a current. $I$, the heat input rate $Q_{h}$ at its hot junction is given by

$$
Q_{h}=K \Delta T+I S T_{h}-I^{2} R / 2 \text {. }
$$

where the first-term represents the zero-current heat conduction, the second term is the Peltier cooling rate of the not junction, and the third term represents one half of the ohmie heat dissipation rate in the couple. Sinilariy, the heat rejection rate $\theta_{c}$ at the couple's cold junction is given by

$$
Q_{c}=K \Delta T+I S T_{c}+I^{2} R / 2 \text {, }
$$

Subtracting Eq. (9) from (8), we obtain

$$
Q_{h} \cdot Q_{r}=I S \Delta T-I^{2} R \text {. }
$$

The couple voltage $\mathbf{V}$ is given by the difference between the open-circuit voltage $S \Delta T$ and the internal voltage drop IR,

$$
V=S \Delta T-I R \text {. }
$$

Eliminating $S \Delta T$ between Eqs. (10) and (11), we obtain

$$
Q_{h}-Q_{c}=I \mathrm{~V} \text {, }
$$

which is consistent with the energy balance for the couple. The couples conversion efficiency $n$ is given by

$$
\eta=\frac{I V}{Q_{h}}=\frac{I V}{K \Delta T+I S T_{h}-I^{2} R / 2} .
$$

Solving Eq. (11) for $I$ and inserting the results into (13), we obtain

$$
\eta=\frac{V(S \Delta T-V)}{K R \Delta T+S T_{h}(S \Delta T \cdot V) \cdot(S \Delta T-V)^{2} / 2}
$$

which is the general solution for the efficiency of a thermoelectric couple, before optimization of its leg area fraction $\alpha$ and its output voltage v. The optinum area fraction $\alpha$ is that value which minimizes the product KR in the denominator of Eq. (14). From Eqs. (6) and (7), that product is given by

$$
K R=k_{n} \rho_{n}+k_{p} \rho_{p}+k_{n} \rho_{p}\left[\frac{\alpha}{1-\alpha}\right]+k_{p} \rho_{n}\left[\frac{1-\alpha}{\alpha}\right] .
$$

Note that for a given set of hot- and coldjunction temperatures the product $K R$, and therefore the efficiency $\eta$, are independent of the leg dimensions $L$ and $A$. The product $K R$ is ninimized when

$$
\alpha_{o p t}=\left[1+\sqrt{\left(k_{n} / k_{p}\right)\left(\rho_{p} / \rho_{n}\right)}\right]^{-1}
$$

Inserting this into Eq. (15), we obtain the minimun value of the product $K R$,

$$
(K R)_{\min }=\left[\sqrt{k_{n} \rho_{n}}+\sqrt{k_{p} \rho_{p}}\right]^{2} .
$$

Inserting Eq. (17) into (14) gives the efficiency $n^{\prime}$ of a couple with optinized leg area fraction,

$$
\eta=\frac{V(S \Delta T-V)}{\left[\sqrt{k_{n} \rho_{n}}+\sqrt{k_{p} \rho_{p}}\right]^{2} \Delta T+S T_{h}(S \Delta T-V)+(S \Delta T-V)^{2} / 2}
$$


The preceding expression is maxinized by setting the couple output voltage equal to

$$
V_{\text {opt }}=\frac{S \Delta T}{1+\frac{1}{\sqrt{(1+Z T)}}},
$$

where $Z$ is the thermoelectric materials' temperature-averaged figure of merit, defined by

$$
Z \equiv\left[\frac{s}{\sqrt{k_{n} \rho_{n}}+\sqrt{k_{p} \rho_{p}}}\right]^{2} \text {. }
$$

and $T$ is the average tenperature

$$
\bar{T}=\left(T_{h}+T_{c}\right) / 2 .
$$

Inserting Eq. (19) into (18) gives the maximun efficiency $h^{*}$ of a couple with optimized leg fraction $\alpha$ and optimized output voltage $V$.

$$
\eta^{*}=\frac{[\sqrt{(1+Z \bar{T})}-1] \eta_{c}}{\sqrt{(1+Z \bar{T})}+1-\eta_{c}},
$$

where $\eta_{c}$ is the Carnot efficiency, which is a function of the absolute hot- and cold-junction tenperatures:

$$
\eta_{c}=1-T_{c} / T_{h} \text {. }
$$

Equations (19) and (22) show that the optimum couple voltage and maximum efficiency are functions of only the thermoelectric material properties and the operating temperatures. Figure 5 presents a semi-log plot_of the voltage ratio $V_{\text {opt }} / S \Delta T$ as a function of $Z \vec{T}$, and Figure 6 presents a $\log -\log$ plot of $n^{*}$ versus 27 for various values of $\eta_{c}$. Figure 5 shows that the matehed-load condition ( $V=0.5$ SAT) does not yield the maximum efficiency. The greater the value of $Z \bar{T}$, the greater the deviation from matched load. Figure 6 shows that $\eta^{*}$ is primarily a function of $2 \overrightarrow{\mathrm{T}}$, and only weakly dependent on $\mathrm{n}_{\mathrm{c}}$.

Figure 5. Effect of Figure of Merit $Z$ on Optimum Load Voltage $\mathrm{V}_{\text {opt }}$

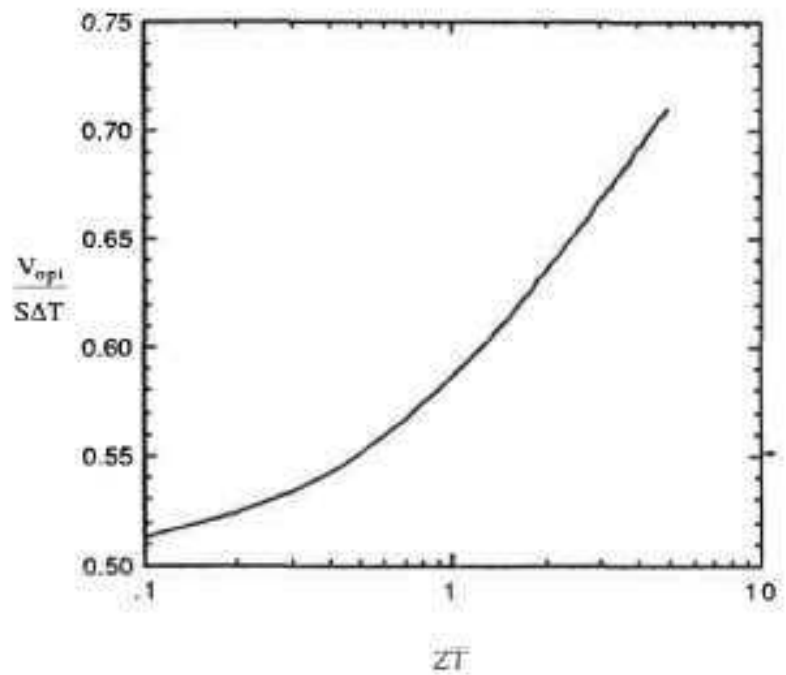

Figure 6. Effect of Figure of Merit $Z$ and Carnot Efficiency $\eta_{c}$ on Maximum Couple Efficiency $\eta^{\prime \prime}$

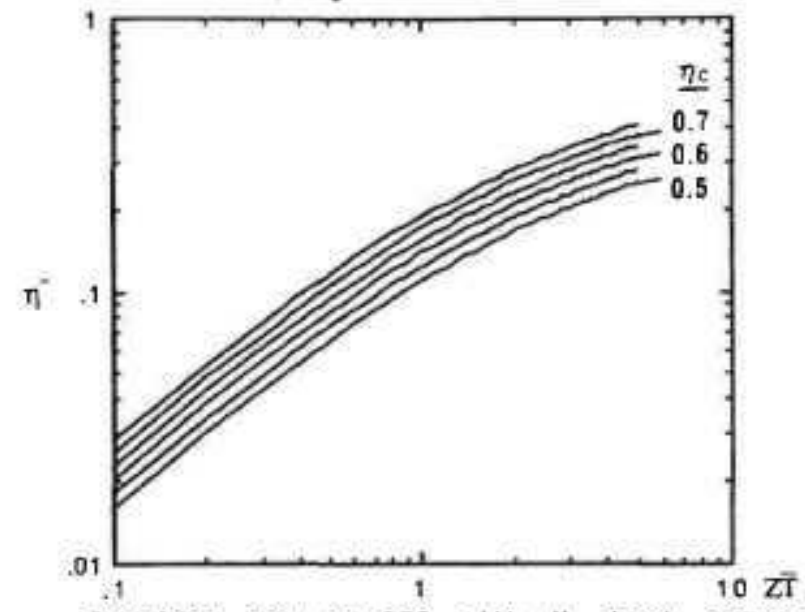

Consider now an RTG with $\mathrm{N}_{\mathrm{m}}$ heat source modules, each having a heat generation rate $q_{\mathbf{n}}$. The RTG's power output $P$ is given by

$$
P=N_{m} Q_{m} \eta_{i} \eta^{\prime \prime}(1-\gamma) \text {. }
$$

where $n_{t}$ is the RTG's thermal efffciency (4.e., the fraction of the generated heat delivered to the thermoelectric iegs), $n^{\prime \prime}$ is the doublyoptimized couple efficiency given by Eq. (22), and $r$ is the fraction of the output voltage lost due to the electrical resistance of the intercouple connectors and RTG terminals. The previous detailed analyses of the baseltne RTG design yielded respective values of 0.88 and 0.06 for $n_{t}$ and $r$. To be consistent, those values were used throughout the material comparison studies.

Given a specified RTG power p. Eq. (24) can be solved for $\boldsymbol{N}_{m}$, the number of neat source modules. But since $\mathrm{N}_{\mathrm{m}}$ must be an integer, the RTG power goal can only be matched approximately. Alternatively, the power goal could be natched exactly, by deviating fros the arbitrarily assumed cold-junction tenperature $T_{c}$ of $300{ }^{\circ} \mathrm{C}$ (by adjusting the radiator $f$ in dimensions).

The RTG has $\mathrm{N}_{\mathrm{p}} \times \mathrm{N}_{\mathrm{s}}$ thermoelectric couples, arranged in a network with $\mathrm{N}_{p}$ couples in parallel and $\mathrm{N}_{\mathrm{s}}$ in series. For geometric reasons, $\mathrm{N}_{p}$ must of course be an integral divisor of the nunber of couples per ring. Given a specified RTG voltage, the number $N_{s}$ of couples in series must satisfy the voltage balance

$$
V_{R T G}=N_{s} V_{\text {opt }}(1-\gamma) \text {. }
$$

where $V_{\text {opt }}$ is the opt imum couple voltage given by Eq. (19). Equation (25) can be solved for the integer value of $\mathrm{N}_{\mathrm{s}}$ which cones closest to yielding the prescribed RTG voltage. Finally, we must solve for the couple's length-to-area ratio which satisfies the RTG's heat balance.

$$
N_{m} Q_{m} \eta_{t}=N_{p} N_{s} Q_{\star} \text {. }
$$

The heat input rate on per couple is given by E.q. (3) in terms of its thermal conductance $K$, electrical resistance $R$, and current $I$. For the 
optimum leg area fraction oopt (Eq. 16) and couple voltage $V_{\text {opt }}$ (Eq. 19), the equations for $K, R$, and $I$ (Eqs. 6,7 , and 11 ) can be reduced to

$$
\begin{aligned}
& K=C_{1}(A / L), \\
& R=C_{2}(L / A), \text { and } \\
& I=C_{3}(A / L),
\end{aligned}
$$

where $C_{1}=k_{n}\left[\frac{1+\sqrt{\left(k_{p} / k_{n}\right)\left(\rho_{p} / \rho_{n}\right)}}{1+\sqrt{\left(k_{n} / k_{p}\right)\left(\rho_{n} / \rho_{p}\right)}}\right]$

$$
C_{2} \equiv \rho_{n}\left[1+\sqrt{\frac{k_{p} \rho_{p}}{k_{n} \rho_{n}}}\right]\left[1+\sqrt{\frac{k_{n} \rho_{n}}{k_{p} \rho_{p}}}\right] \text {, and 31) }
$$

and $\quad C_{3} \equiv \frac{S \Delta T / C_{2}}{\sqrt{1+Z \bar{T}}+1}$

Inserting Eqs. (27), (28), and (29) into (8) and solving for $L / A$ we obtain the expression

$$
L / A=\left[C_{1} \Delta T+C_{3} S T_{h}-C_{2} C_{3}^{2} / 2\right] / Q_{h}
$$

for the required length-to-area ratio of the couples.

For each of the materfals listed in the previous section, the preceding equations were solved for the RTG design parameters $\left(\mathbf{N}_{m} . N_{p} . N_{s}\right.$. $\alpha$, and A) and for the resultant perfolmance parameters (I. V, P, $\eta^{*}$ ) and the RTt's mass and specific power. The computed results are presented in the next section.

Tabie 8. Effect of Thermoelectric Figure of Merit on RTG Design and BOM Pertormance

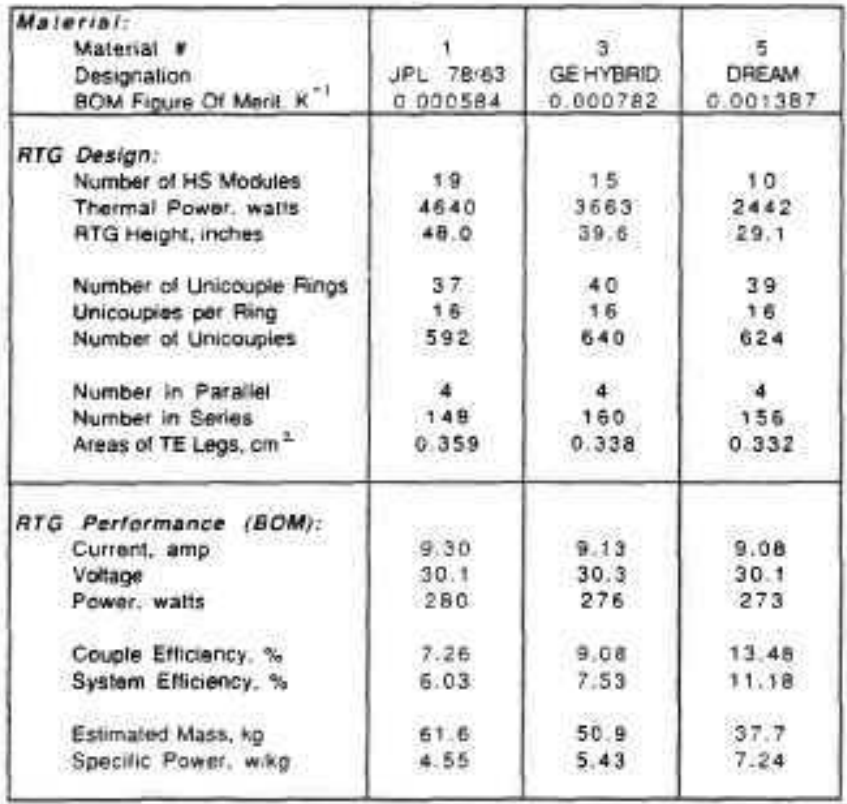

Results and Conclusions: Comparison of the five RTG designs showed, not surprisingly, that Materials 2, 3, and 4 yieided very similar results. Therefore, only the results for options 1. 3 , and 5 are presented below. Table 8 compares their performance, and Table 9 compares their mass breakdown.

Comparison of columns 1 and 2 of Table 8 shows that the addition of GaP in the SiGe n-leg produces very significant effictency increases. For the sane output power, these lead to substantial reductions in fuel loading and RTG mass.

Comparison of Columns 2 and 3 shows that the hypothetical and still undefined "dream" material would result in even greater efficiency increase, and correspondingly much larger reductions in fuel loading and RTG mass.

Multicouples employing Sige/GaP $n$-legs have already been built and tested for 6000 hours. They exhibited stable perfornance under positive bias, but anonalous degradation under negative. bias with respect to the RTG housing. Thus, they could be considered for use in RTGs in which all multicouples were maintained under positive bias. But if it were deemed too risky to fly a multicouple RTG until the negative-bias anomaly is more fully understood and resolved, Table 8 shows that the use of SiGe/Gap n-legs would still be quite advantageous for use in unicouple RTGS. Such unicouples have not yet been built, and would require stgnificant nev bond developments. But the programmatic risk of doing that seems

\begin{tabular}{|c|c|c|c|}
\hline 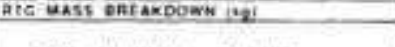 & 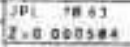 & 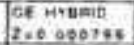 & 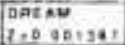 \\
\hline \multicolumn{4}{|l|}{ 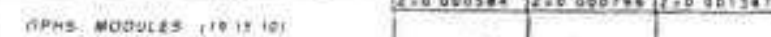 } \\
\hline Wor hingt & $\cdots, 7$ & ont & sne \\
\hline 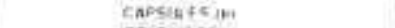 & t.24 & 151 & 214 \\
\hline crumestes & +17 & +26 & Ett \\
\hline \multicolumn{4}{|l|}{ HS CANESTEN Nar } \\
\hline gide wails & 2.22 & t.84 & $n$ \\
\hline Elows & 011 & $3 \%$ & e*t \\
\hline 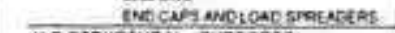 & $\because \mathrm{AE}$ & ing & .45 \\
\hline \multicolumn{4}{|l|}{ 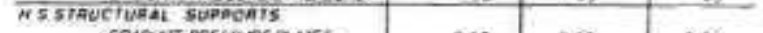 } \\
\hline CALATIE PGESSUPE MUAES & esi & $0 \%$ & 0.53 \\
\hline 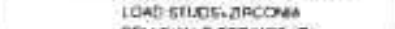 & $c=8$ & $a \rightarrow$ & 07 \\
\hline BELLEMLLE SPRATSS IT: & 264 & 78 & 035 \\
\hline CDEAPRE CNO VKROMARE. & Das & E.t. & Ba \\
\hline \multicolumn{4}{|l|}{ ELECTRUCAL CIRCUITS } \\
\hline 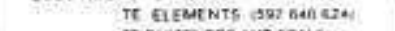 & 503 & 3 & $+\infty$ \\
\hline TE FASIEME AS ANC SEALS & +12 & .22 & $x+n$ \\
\hline aLinma nusuca TCAS. & 090 & $0 \%$ & 00 \\
\hline 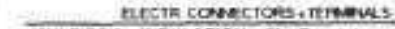 & 039 & D.11 & sa: \\
\hline \multicolumn{4}{|l|}{ 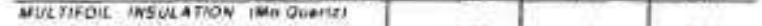 } \\
\hline 5605 & 333 & 40 & 362 \\
\hline PQDE & 0.59 & 0.48 & $86 \theta$ \\
\hline \multicolumn{4}{|l|}{ Fta HOVISINC IAI } \\
\hline 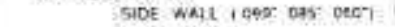 & in $n$ & 528 & 321 \\
\hline ENOSECTON & $0 \times \pi$ & 0.7 & Qe? \\
\hline cosisas & Q98: & a), 9 & 0,0 \\
\hline AESISTUKE DEPAOCNETEA. & $a>0$. & 930. & a. 50 \\
\hline Casuat assfuel, & Eit & $0 \times$ & 6 is \\
\hline \multicolumn{4}{|l|}{ नसOATOF } \\
\hline Fins inat & 267 & $2: 16$ & is 55 \\
\hline Aixe war tore am naser or os & 230 & 624 & $0 \geq 8$ \\
\hline PASswity contring & $=1.5$ & Iis & G. $\mathrm{k}$ \\
\hline vorAh Massiksi & ciss & 50 16 & $2 \pi 72$ \\
\hline
\end{tabular}
reasonable and well justified by the potential payof $f$.

Table 9. Effect of Thermoelectric Material on Mass of Unicouple RTE 
As for the dream material, the payoff would obviously be much greater. But they would require development of new material fabrication methods, bonding techniques, fabrication procedure, and extensive testing to demonstrate the couples' performance, reproducibility, compatibility with other RTG components at operating temperatures, and long-term performance stability. In the absence of any infornation about materiat compositions and development approach, the authors are unable to assess the ultimate success probabtlity of such a development program, But, based on their extensfve experience on numerous other RTG development programs, they are convinced that a program to develop a flight RTG employing this material would not cone close to seeting the JPLenvisaged MRSR schedule described in Figure 2 of Reference [1].

\section{REFERENCES}

[1] A. Schock, V. Sankarankandath, and M. Shirbacheh, "Requirements and Designs of Mars Rover RTGs." 24th Intersociety Energy Conversion Englneering Conference, 6-11 August, 1989 .

[2] A. Schock and T. Banrick, "Structura] Design and Analysis of Mars Rover RTGs." Ibid.

\section{ACKNOWLEDGEMENT}

The above work was supported by the U.S. Department of Bnergy's office of Special Applications. 


\title{
STRUCTURAL DESIGN AND ANALYSIS OF MARS ROVER RTGS
}

\author{
A. Schock, T. Hamrick
}

Fairchild Space Company. Germantown, MD

ABSTRACT

The paper presents the structural design and analys1s of the Rover RTGs described earlier at this conference. Of particular importance are the axial preloads reguired to hold the stacked heat source modules together during Earth launch, Mars landing, and Mars roving. The paper describes the design and stress analysis of the heat source support structure, including the preload springs, and of the housing wall which supports the base-mounted cantilevered RTG. Although the Mars roving case produces lower $G$-loads than Earth launch, this case must also be analyzed and designed for, because the RTG cooling mode and RTC housing temperatures change after Mars landing, and the spring length and spring force w111 change correspondingly. The structural analysis and design were 1terated to artive at a configuration that meets the design requirements.

\section{INTRODUCTION}

The Martian Rover is part of the Mars Rover and Sample Return mission (MRSR) under study at the Jet Propulsion Laboratory (JPL) for the National Aeronautics and Space Administration. At JPL's request, the Department of Energy's office of Special Applications conmissioned Fairchild to perform a design study of RTGs to power the Rover.

Two companion papers presented at this conference described varfous RTG designs [1] and their thermal, thermoelectric, electrical, and mass analyses [2]. The present paper describes the structural design and analysis of those RTGs.

All RTG designs generated in the Fairchild study employ the General Purpose Heat Source (GPHS) module as the basic heat source building block. Each GPHS module produces 250 watts $(t)$, and as many as 18 stacked modules are contained in each RTG. As shown in Figure 1, each module is contained in a graphite aeroshe11. with outer dimensions of 3.8 by 3.7 by 2.1 inches. The aeroshell serves as the structural member of the heat source module. The inner components contribute to the GPHS mass and the inertial forces, but play no significant structural role.
Figure 1. General-Purpose Heat Source Module (250 Watt)

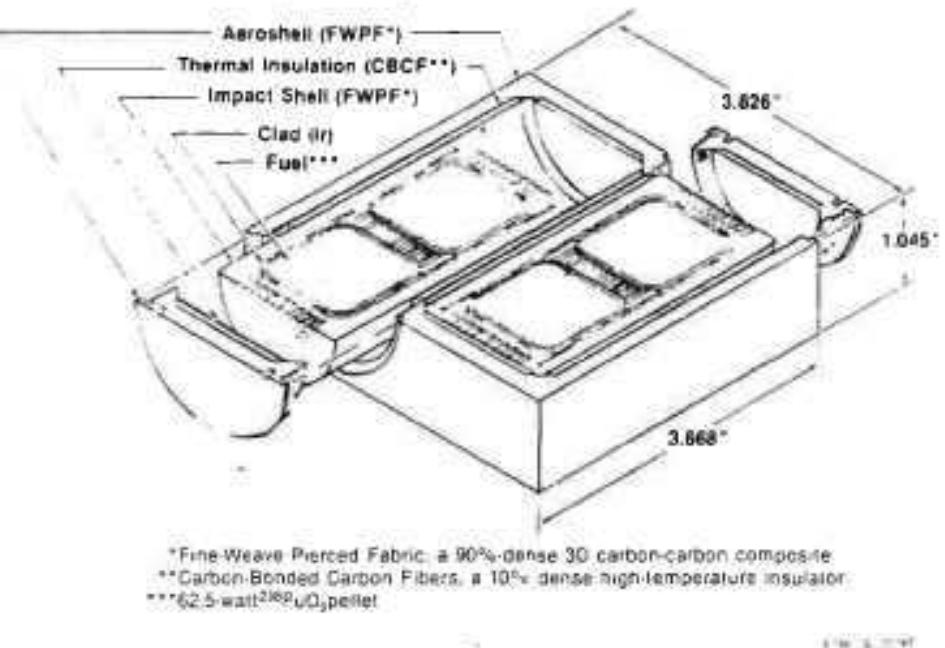

The GPHS module design is primartily driven by safety considerations. The modules are designed to survive hypersonic reentry and subsequent Earth impact without fuel release. To maximize the impact safety margin, one wishes to minimize the impact velocity. Individual nodules have a much lower impact velocity $(49 \mathrm{~m} / \mathrm{s})$ than the stacked heat source $(74 \mathrm{~m} / \mathrm{s})$. Therefore, it is desirable to support the heat source stack in such a manner that the individual modules separate during reentry. This is accomplished by structurally supporting the heat source stack from the RTG's aluminum housing, which melts during reentry, releasing the modules. But the same support structure must hold the stacked modules together during launch and operational vibration and shock loads.

The heat source support arrangement will be described in detall with respect to the baseline RTG design described in Reference [1]. That design contains 18 heat source modules and 576 thermoelectric unicouples, and produces 250 watts(e) at the end of the MRSR mission, based on demonstrated thermoelectric technology and measured performance levels. 
Figure 2 shows horizontal and vertical cross-sections of the baseline RTG design. As indicated by the line $C-C$ in the horizontal section, the left half of the vertical section represents a nornal cut through the heat source stack, and the right half represents a diagonal cut. For the sake of clarity, oniy three of the eighteen modules are depicted in Section $\mathrm{C}-\mathrm{C}$. As indicated in that section, there are two horizontal cuts. Section A-A shows a cut through the center of a heat source nodule, and Section a-B shows the upper heat source support structure, Both show a cut through a layer of thermoelectric unicouples, and through the RTG housing and radiator fins. The left half of Section $C-C$ shows the length of the water-cooled RTG housing, and the right half shows its radiation-cooled length.

Figure 2. Baseline RTG Cross-Sections, Showing

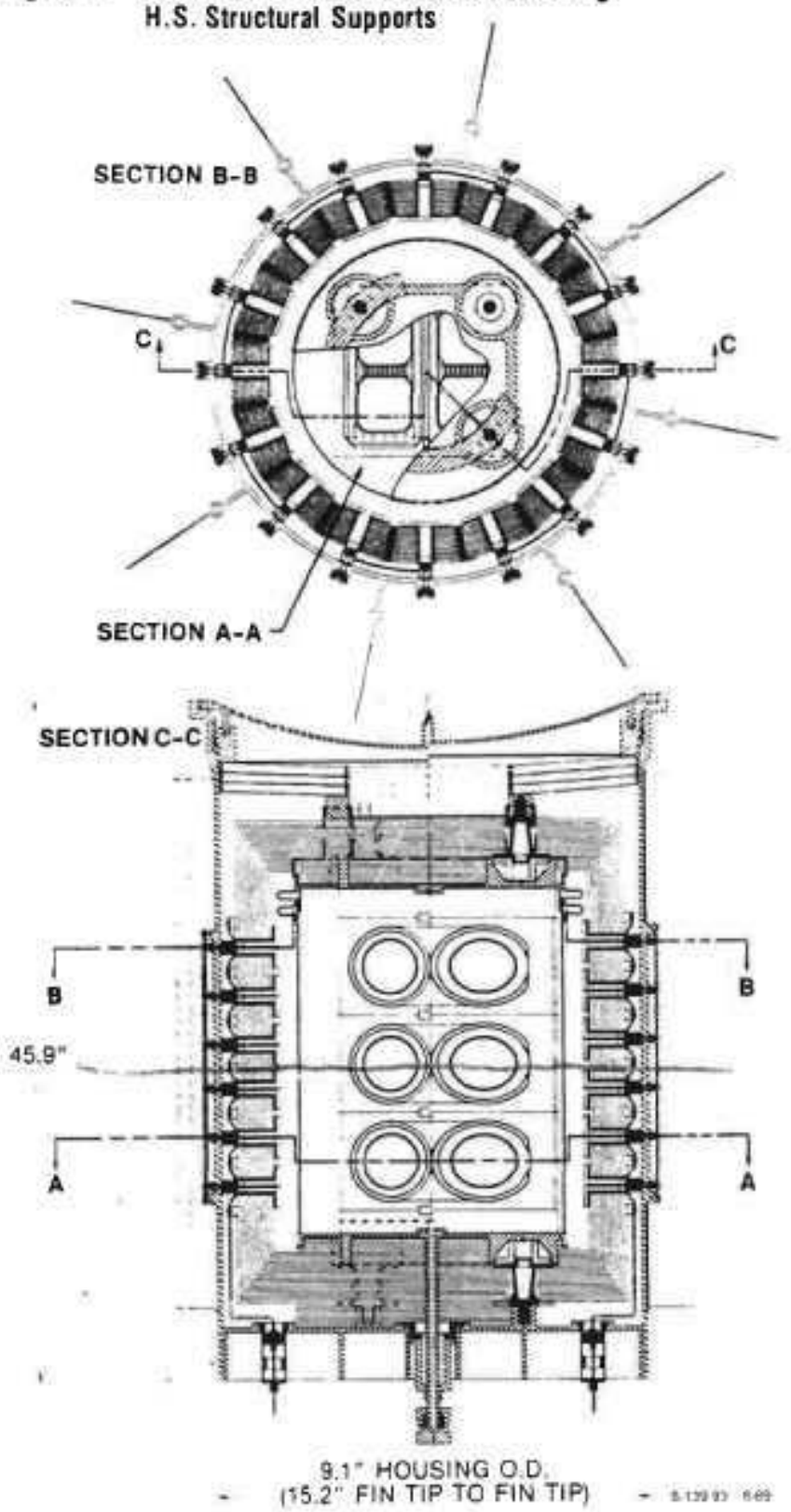

As shown, the heat source stack is only supported at its ends. There are no midspan supports. The heat source support structure is designed to hold the modules together under lateral loads of 25 G during Earth launch and 15 G during atmospheric entry, landing, and surface travel on Mars. This is done by using a set of Belleville springs to subject the stack to a large axial preload. The heat source canister serves only as a helium container. Its thin side wall plays no structural role.

Figures $3 \mathrm{a}$ and $3 \mathrm{~b}$ present sectional trimetric closeups of the support structure at the top and botton of the heat source stack. Figure 3 a shows an exploded view of the upper structure, and Figure $3 b$ shows the bottom structure, viewed from below. The multifoli thermal insulation has been onitted for clarity.

Figure 3a. Exploded View of Support Structure at Top of Heat Source

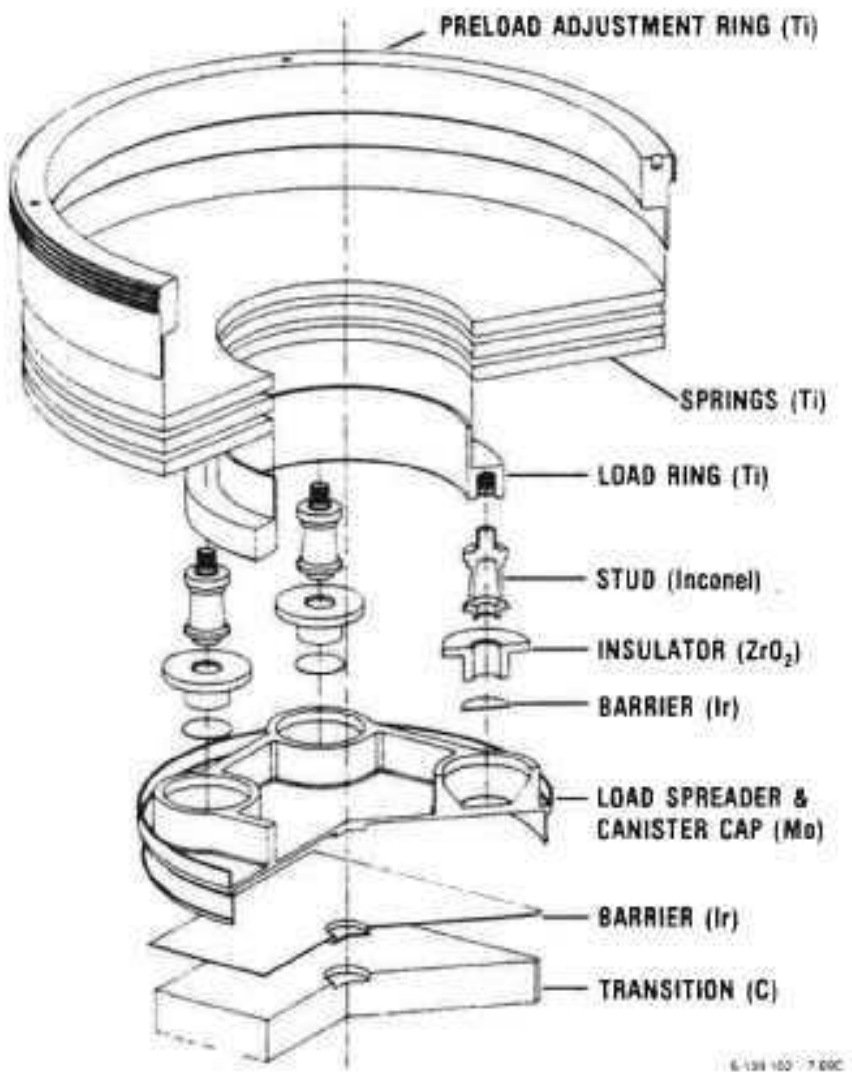

As shown, the first and last heat source modules are followed by graphtte transition sections. Those transitions bear against the end caps of the molybdenum canister. Thin iridium sheets are used as reaction barriers between the graphite and the molybdenum.

On the outside of each of the canister end caps is a set of integral stiffening ribs and load stud seats. These form a square structure, to spread the axial load from the four load studs to the four edges of the heat source end face. 
The axial load is applied by the four Inconel load studs via zirconia insulators, to reduce the axial heat losses and the load stud temperatures. As shown in Figure 2 , the studs penetrate through the multifoil thermal insulation.

The upper set of load studs is bolted to a titanium load ring. As shown in Figure $3 a$, the axial preload force is applied to the load ring by a set of titanium Belleville springs, which bear against a preload adjustment $r$ ing that is threaded to the I.D. of the RTG's aluminum housing. After the load is set, the ring is prevented from backing off by anti-rotation pins.

The lower set of load studs is bolted directly to the baseplate of the RTG's aluminum housing. which has integral radial and circunferential stiffening ribs, as shown in Figure $3 b$.

Figure 3b. Exploded View of Support Structure at Bottom of Heat Source

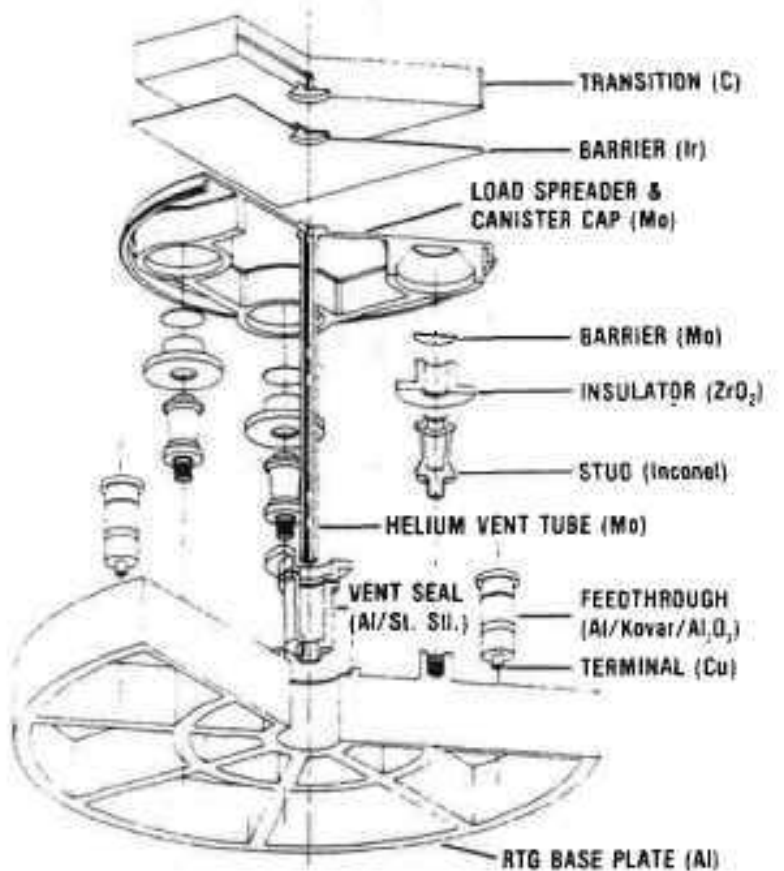

nis wa $+a x$

The structural design of the RTG consists of three principal tasks:

1. Determining how large a preload is required to hold the noduies together during Earth launch and during Mars operations.

2. Designing the Belleville springs to supply the required spring force and spring travel.
3. Designing the RTG housing to withstand the bending moments on the cantilevered RTG during launch, to be structurally stable against the one-atmosphere external pressure, and to stay below the stresses where longterm creep would occur at the materials. operating temperatures.

These tasks are described in the next three sections.

DETERMINING THE REQUIRED PRELOAD FDRCES AND RESULTANT GRAPHITE STRESSES

The heat source stack may be viewed as a partitioned beam with a distributed side load. If the beam were continuous rather than partitioned, the side load would produce axial compressive stresses on the side to which it is applied, and axial tensile stresses on the opposite side. But a partitioned beam cannot sustain a tensile stress in the axial direction. Therefore, in the absence of an axial preload, the side load would cause the partitioned beam to fall apart.

To hold the heat source stack together in the RTG. the axial preload must be high enough to equal or exceed the maximum tensile stress produced by the side load. When this principle was first applied [3], the authors mistakenly treated the GPHS module as though it vere a solid block rather than a hollow box. This can lead to a serious overestimate of the required preload. as 1 lifustrated belor.

Consider the simplified case of a hollow beam having a length $L$ and cross-section bounded by an outer square of side a and concentric inner square of side b. The beam has fixed end supports and a uniform distributed side load " per unit length. Its maximum bending moment $M$, which occurs at the beam's ends and at its center, is given by

$$
M=w L^{2} / 24 .
$$

Its maximun tensile stress $\sigma$ is given by

$$
\sigma=M c / I \text {. }
$$

where $c$ is the distance from the center to the outer fiber,

$$
c=a / 2 \text {, }
$$

and $I$ is the cross-section's moment of inertia, given by

$$
I=\left(a^{4}-b^{4}\right) / 12 .
$$


If the beam is partitioned (i.e., an unbonded stack). it will hold together if the compressive stress produced by the preload $P$ equals the tensile stress $\sigma$. Hence,

$$
P=\sigma\left(a^{2}-b^{2}\right) \text {. }
$$

Combining Equations (1) through (5), we obtain the formula

$$
P=\frac{w L^{2}}{4 a\left[1+(b / a)^{2}\right]}
$$

for the required preload $P$.

Clearly, increasing the size of the cavity in the hollow beam decreases the required preload. Equation (6) shows that in the linit, as b approaches $a$, the required preload for the hollow beam is only half as large as that for a solid beam $(b=0)$. This principle had been overlooked in Reference [3], but was recognized by $\mathrm{Mr}$. Hamrick during the present study. It can make the difference between requiring or not requiring a midspen support.

The above derivation was for the idealized case of a simple hollow box bean. The nodular heat source stack is more complicated. As shown in Figure 1, each module has top and bottom covers, and a curved cavity resulting in nonuniform side walls. To determine the required preload for such a modular stack, a detailed NASTRAN analysis was carried out, enploying three-dimensional models of the modules? aeroshells and orthotropic properties of the carbon-carbon composite.

Figure 4 shows the undeformed grid model for half of the aeroshell of a single module. This and subsequent figures are sectioned at the plane of symetry, the $y-z$ plane. The appropriate number of such models were stacked up, linked to each other, and combtned with models of the heat source support structure. The integrated node? was then suojected to the axial spring load and to 8 side load of $25 \mathrm{G}$.

Figure 4. Nastran Model of GPHS Aeroshell

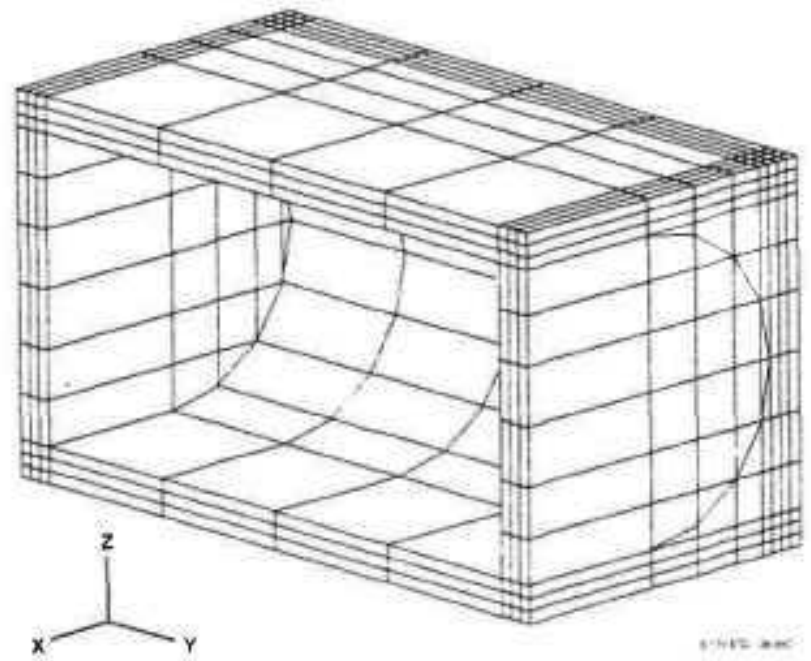

For a preitiminary analysis, the heat source stack was analyzed without the effect of the simultaneous defornation of the cantilevered RTG housing. This simplification cuts the problem in half, because it results in identical end supports and symmetry about the heat source's nidplane. Therefore, only half the neat source nodules need to be modeled.

At the time of the preliminary analysis, we were considering a heat source of 16 instead of 18 modules. Therefore, our preliminary-analys is model consisted of eight heat source modules. The 16-module stack was subjected to a 4000-1b axial preload. The resultant deformation of the upper half of the 16-module stack is shown in Figure 5.

Figure 5. Deformation of Upper Halt of Heat Source Stack Under 4000-10 Axial Load and 256 Side Load (Y)

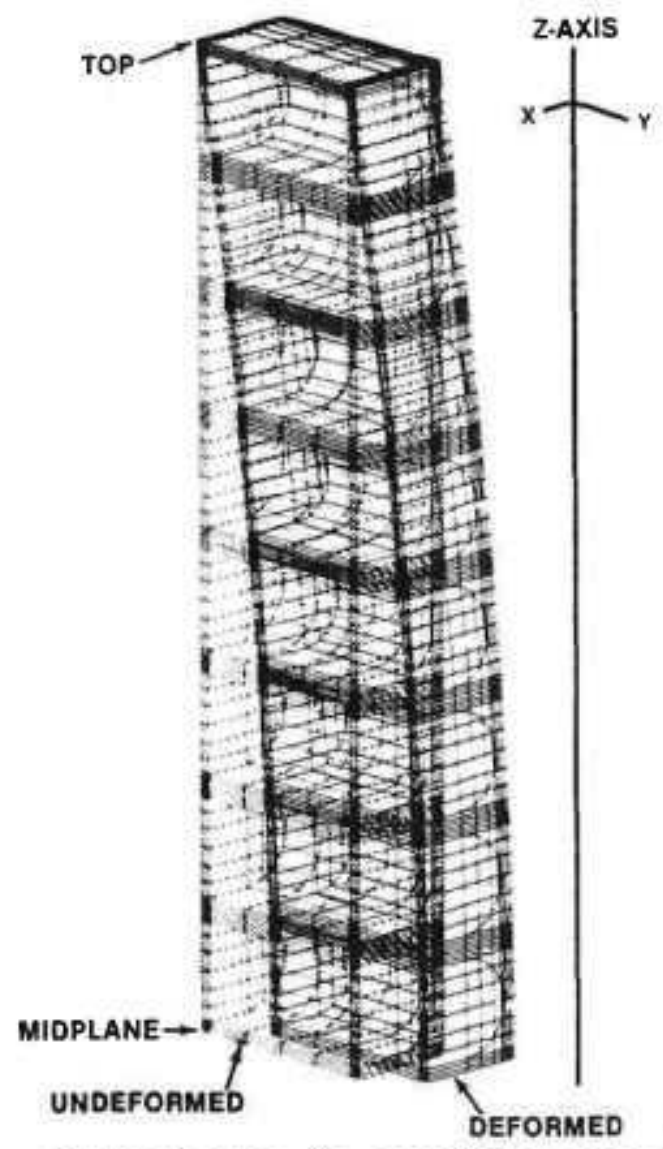

Man $*$ ox

Figure 6 shows the normal $Z$-stresses in the first and eighth heat source modules. As can be seen, all $z$-stresses are negative (1,e.. compressive) except for one sma11 section in the upper left corner of Module 1 , which shows a tensile stress of $0.53 \mathrm{ksi}$. It was therefore concluded that the basic principle illustrated by Ea. (6) had been confirmed, but that the predicted $4000-10$ preload is slightly inadequate for the 16-module heat source. Based on these results, it was decided to use a $5500-16$ preload for the 18-module heat source in subsequent analyses. 
Figure 6. Normal 2-Stresses in End and Center GPHS Modules
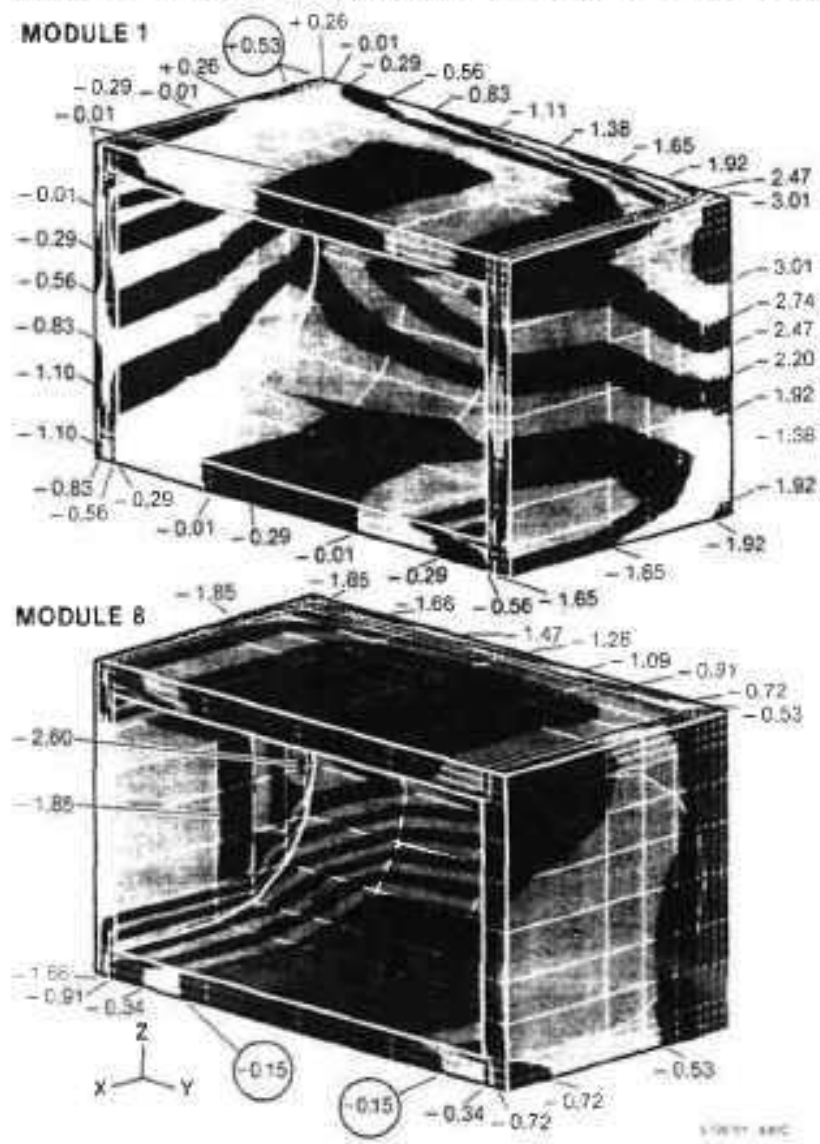

The same analytical model was used to compute the von Mises stresses in Modules 1 through 8. The naximum was found to occur in Module 1. Figure 7 shows the von Mises stresses in that module.

Figure 7. Von Mises Stresses in Module 1

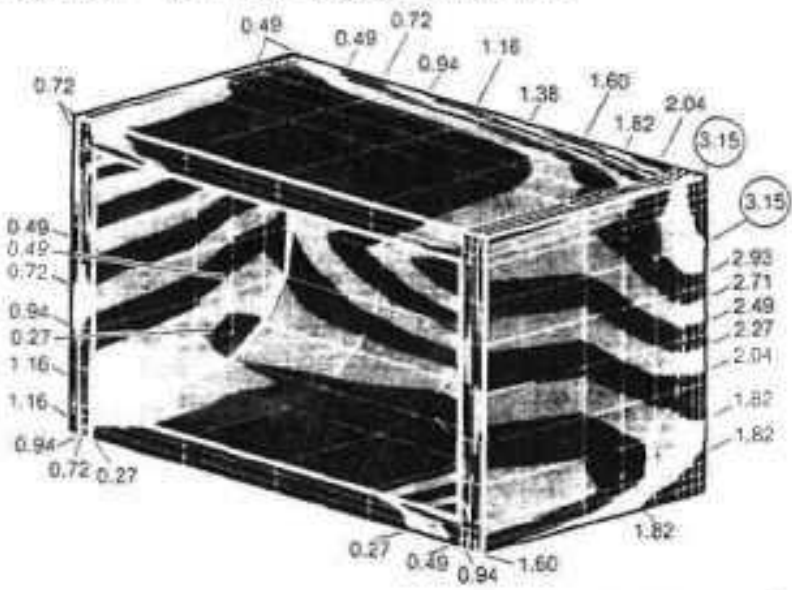

As can be seen, the maximum von Mises stress, in the upper right corner or Module $\# 1$, is $3.15 \mathrm{ksi}$. This is well within the tensile and compressive strengths of the Fine-Weave Plerced Fabric (FWPF) graphite moterial, as shown in Table 1, which was supplied by its manufacturer AVCO.
Table 1. Composite Strength (ksi) of AVCO Fine-Weave Pierced Fabric

\begin{tabular}{|c|c|c|c|c|c|c|c|c|}
\hline \multirow[t]{2}{*}{ TEMFERLTURE } & G5 & 75 & 600 & 1000 & 2000 & 3000 & 4000 & 5000 \\
\hline & "c & 26 & 596 & 537 & 1096 & 2645 & 2206 & 2760 \\
\hline \multirow[t]{3}{*}{ TENSEDS } & $Y$ & 1774 & 1066 & 20,65 & $23 \mathrm{BE}$ & 76.21 & 27.39 & 25.28 \\
\hline & $x$ & $170 t$ & $39 . E E$ & 20.06 & 20.56 & $26:$ & 57 $3 E$ & 25,20 \\
\hline & 2 & 18.77 & 2024 & 21.24 & 2457 & off 99 & 28.20 & 25.95 \\
\hline \multirow[t]{3}{*}{ COMPRESSIOS } & Y & 2051 & 2078 & 2065 & 21,50 & 2356 & $2 \mathrm{f}: 49$ & $30 \mathrm{F:}$ \\
\hline & $x$ & $2 \cdot 5 t$ & 2506 & 20.85 & $2+34$ & 2356 & 2649 & $306:$ \\
\hline & 2 & 20.8 & 210 & 2117 & 2) 69 & 25.98 & $26 \mathrm{be}$ & $2+30$ \\
\hline \multirow[t]{3}{*}{ SHEAR: } & $y_{2}$ & 117 & 111 & $: 07$ & 100 & [1996 & $12 \mathrm{E}$ & 100 \\
\hline & $Z x$ & 1.4 & 711 & 157 & $t D 0]$ & $p, 09$ & 125 & 100 \\
\hline & $x$ & 117 & 511 & $15 ?$ & 100 ? & 0.97 & $12 t$ & 10 \\
\hline
\end{tabular}

Table 1 shows that FWPF is much weaker in shear than in tension or compression. Therefore, the $x y, x z$, and $y z$ shear stresses were computed, and found to be a maximum in Module 1. The three sets of shear stresses in that moduie are shown in figure 8. The naximum shear stress of 0.138 ksi is only $14 \%$ of the material's shear strength, as shown in Table 1 .

Figure 8. Module-1 Shear Stresses, in ksl

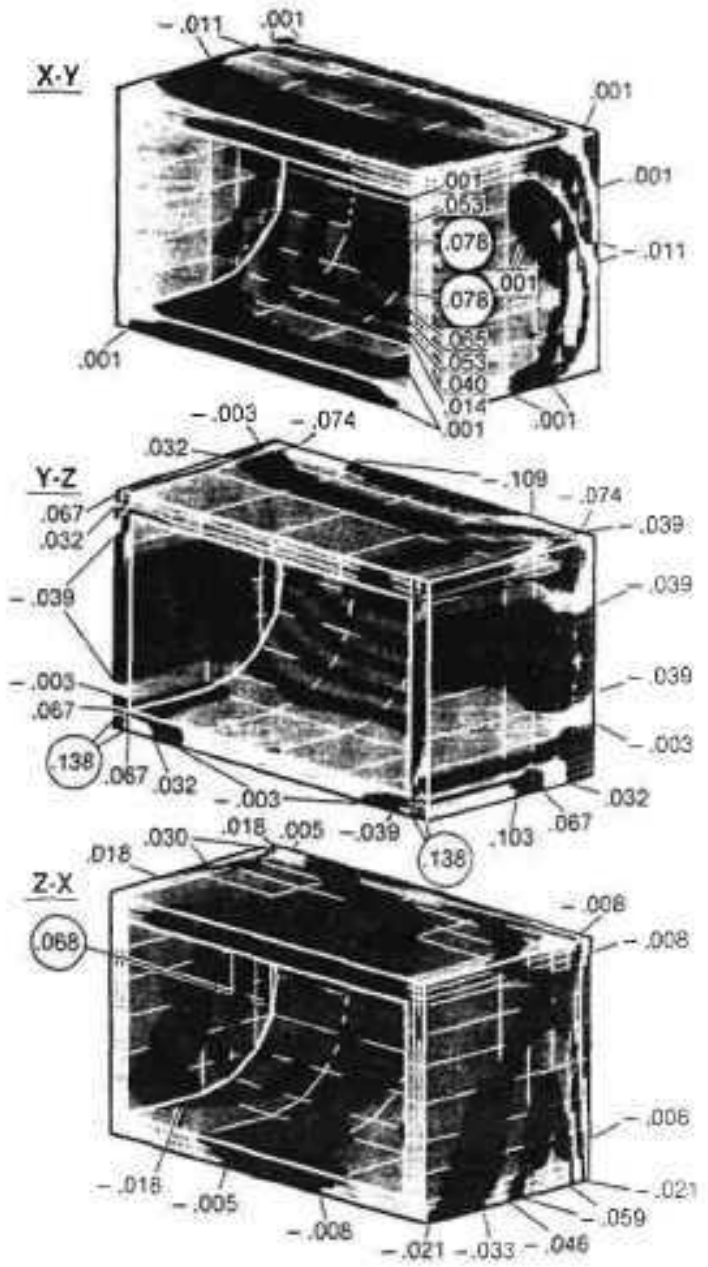

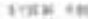




\section{DESIGNING THE BELLEVILLE SPRINGS}

The Mars Rover RTC design differs from other RTGs in that a preload is required not fust for a brief period during Earth launch. but aiso during atmospheric entry and landing on Mars and during Rover activities on Mars for the full four-year duration of the MRSR mission. Although the G-ioads during these post-launch operations (15 G) are lower than during launch $(25 \mathrm{G})$, one cannot assune that springs which satisfy the higher requirement will automaticaliy satisfy the lower. This is so because the Rover RTG is. water-cooled during Earth launch and radiationcooled during and after Mars landing, as explained th Reference [1].

In switching fron water-cooling to radiation-cooling, the RTG's housing temperature rises by about $100^{\circ} \mathrm{C}$, causing its length to grow by about $0.1^{*}$. Since the thernal expansion of the graphite heat source is virtually negligible, the thermal growth of the aluminum housing causes a corresponding expansion of the Belleville preload springs, and consequently a relaxation of the compressive load on the heat source stack.

Therefore, the designer must consider the adequacy of the spring force both during launch and during subsequent Martian operations, at theit respective RTG tenperatures. At the same time, he must make certain that the maximun stress in the spring material under maximum-load conditions does not exceed the spring naterial's strength at temperature. Thus, the spring design must satisfy three independent constraints.

Consider a set of $\mathbf{N}_{5} \times \mathbf{N}_{\mathrm{p}}$ conical cBellevilie) springs of outer diameter $\mathrm{D}_{0}$ inner dfaneter $D_{i}$, and thickness $T$. The spring set is arranged with $\mathrm{N}_{\mathrm{p}}$ springs in parallei (i.e. nested) and $\mathrm{N}_{\mathrm{s}}$ in series (i.e., stacked). The springs are made of a material with elastic modulus $E$ and Poisson's ration $\mu$. The overa 71 free height of each spring is $\mathrm{H}+\mathrm{T}$. The deflection of each spring from its free height during Earth launch is $Y_{e}$ During Martian operations, the deflection of each spring from its free length is given by

$$
Y_{m}=Y_{c} \cdot \delta / N_{s} \text {, }
$$

where $\delta$ is the thermal growth of the aluminum housing length due to the change from water cooling to radiation cooling.

The load $P_{e}$ exerted by the set of springs during Earth launch is given by [4]

$$
P_{c}=\frac{N_{f} E Y_{e}\left[\left(H-Y_{d} / 2\right)\left(H-Y_{e}\right) T+T^{3}\right]}{\left(1-\mu^{2}\right) C_{0}\left(D_{o} / 2\right)^{2}},
$$

the corresponding load $P_{n}$ during Martian operations is given by

$$
P_{m}=\frac{N_{p} E Y_{n i}\left[\left(H-Y_{m} / 2\right)\left(H-Y_{m}\right) T+T^{3}\right]}{\left(1-\mu^{2}\right) C_{0}\left(D_{o} / 2\right)^{2}}
$$

and the maximum stress o (at the inner diameter of the springs) is given by

$$
\sigma=\frac{E Y_{e}\left[C_{1}\left(H-Y_{e} / 2\right)+C_{2} T\right]}{\left(1-\mu^{2}\right) C_{0}\left(D_{n} / 2\right)^{2}},
$$

where $c_{0}, \quad c_{1}$ and $c_{2}$ are dimensionless geonetric constants defined by

$$
\begin{aligned}
& C_{0} \equiv \frac{6\left(1-D_{i} / D_{o}\right)^{2}}{\pi \ln \left(D_{o} / D_{i}\right)}, \\
& C_{1} \equiv \frac{6}{\pi \ln \left(D_{o} / D_{i}\right)}\left[\frac{D_{o} / D_{i}-1}{\ln \left(D_{o} / D_{i}\right)}-1\right], \text { and } \\
& C_{2} \equiv \frac{3\left(D_{o} / D_{i}-1\right)}{\pi \ln \left(D_{o} / D_{i}\right)} .
\end{aligned}
$$

Thus, given the values of $\mathrm{N}_{p}, \mathrm{~N}_{\mathbf{s}}, \mathrm{D}_{0}, \mathrm{D}_{\mathbf{i}}$, $P_{e}, P_{m}$ and 8 , the spring design problem comes down to solving the three equations ( 8,9 , and 10) for the unknown spring dimensions $T, H$. and $Y_{e}$ - Since these are simultaneous cubic equations, a trial-and-error solution is required. This was 4 mplemented by means of a Fatrchild-generated computer program, The parameters used in the computations for the 18-module baseline RTG are summarized below:

$$
\begin{array}{ll}
E=11 \times 10^{6} \text { psi } & \delta=0.100 \text { in } \\
\mu=0.31 & \sigma=82 \mathrm{ksi} \\
\mathrm{P}_{\mathrm{e}}=5500 \mathrm{lb} & \mathrm{D}_{0}=8.75 \mathrm{in} \\
\mathrm{P}_{\mathrm{m}}=3300 \mathrm{lb} & \mathrm{D}_{\mathrm{i}}=3.20 \mathrm{in}
\end{array}
$$

The spring's outer diameter $D_{c}$ is designed to mate with the I.D. of the RTG housing, and its inner diameter $D_{i}$ is designed to mate with the load ring to which the heat source support studs are bolted. Thus, the springs act as the radial support of the top of the heat source. (See Figure 2). To retain this benefit, an odd number was always picked for $\mathbf{N}_{\mathbf{s}}$, the number of springs (or nested springs) in series. Thus, the spring set is always loaded on the D.D. at the top and

\begin{tabular}{|c|c|c|c|c|c|c|c|c|}
\hline fis & 1 & 1 & 1 & 3 & 3 & 3 & 3 & \\
\hline$N=$ & 1 & 4 & 5 & 1 & $z$ & 3 & 4 & \\
\hline$T$ & 221 & 134 & 058 & 153 & 061 & 638 & 028 & Fed \\
\hline H & 230 & 357 & 414 & 742 & $89 t^{\circ}$ & 921 & 533 & isch \\
\hline$\gamma_{1}$ & 176 & 151 & 163 & 076 & 077 & 027 & 077 & wes \\
\hline$Y_{e j}$ & 076 & 061 & 053 & 043 & 044 & 0.4 & .046 & inct \\
\hline
\end{tabular}
on the I.D, at the bottom.

For a given set of spring parameters. varfous combinations of $\mathrm{N}_{s}$ and $\mathrm{N}_{\mathrm{P}}$ were tested. For sone combinations, it was found that no physically real solution exists. But in general, there were several different combinations of $\mathbf{N}_{s}$ and $N_{p}$ which satisfied the three equations and therefore the three constraints. For example, for the above parameters the equations are satisfied by the alternative solutions listed in Table 2.

Table 2. Spring Design Options Satisfying the Constraints on $P_{E}, P_{M}$, and $\sigma$ 
Each of the options listed in the table yields a preload of 5500 los on Earth, 3300 los on Mars, and a maximum stress of $82 \mathrm{ksi}$ at the spring's I.O. Thus, any one of these options could be adopted. However, we preferred a single set of nested springs to a multiple stack, because it leads to a simpler and nore compact RTG design.

Among the solutions for $N_{S}=1$, we selected the one with the least number of springs, $\boldsymbol{N}_{s}=3$. Note that there is no physically real solution for $N_{s}=1$ and $N_{p}=1$ or 2 . Thus, the spring design for the baseline RTG consists of three nested springs, with each spring having a thickness $T$ of $0.221^{*}$, a free height $H+T$ of $0,451 "$, and a compressed height $\left(H+T-Y_{e}\right)$ of $0.275^{\circ}$ during Earth launch and $\left(H+T-Y_{m}\right)$ of $0.375^{*}$ during Mars operations.

DEFORMATION AND STRESSES WITH HEAT SOURCE SUPPORTED BY CANTILEVEREO RTG HOUSING

The preliminary structural analysis described thus far employed a simplified analytical madel. The nodel did not include the RTG housing, which supports the load springs that compress the heat source stack. Instead, the load springs were assumed to have symnetrical fixed-end supports. Because of that symmetry, only half the heat source stack needed to be modeled.

The more complete analysis described in this section does not employ these simplifications. The heat source is supported by the deformable RTG housing. Specifically, the upper springs are connected to the top of the housing side wall, and the lower heat source support studs are mounted on the housing baseplate.

The model of the housing includes the fin roots and cooling ducts which act as stiffeners. It also includes the radial and circunferential stiffeners of the baseplate. The housing is cantilevered, with only the $\mathrm{rim}$ of its baseplate fixed, and the rest of the housing free to lean away from the $25 \mathrm{G}$ side load. The resultant anguTar deflection of the RTG's upper end results in highly unsymmetrical heat source supports. Therefore, it was necessacy to model the whole 18-module heat source.

The solids model used for the preliminary analysis of the eight-module half-stack had 10,961 grid points and 26,652 degrees of freedom. Using a similar solids model for the full eighteen-module heat source would have exceeded the available computer time and disk space. To avoid that, the solids model was replaced with a plate model having an equivalent stiffness matrix. Even so, a very large (2140-node) NASTRAN model with 10,611 degrees of freedom was required to represent the heat source, its support structure, and the RTG housing.
Figure 9 depicts the model of the ATG in its undeformed and deformed shapes. The defornation shown includes the effects of the $25-6$ side load and of the 5500-7b spring force, which produces a compressive load on the heat source stack and a tensile load on the housing. The deformations shown have, of course, been exaggerated for improved visibllity. Note the leaning of the housing and the bowing of the heat source in the $y$-direction, the axial elongation of the housing due to its tensile load, and the outbowing of the RTG's baseplate due to the downward force exerted by the heat source.

Figure 9. Deformation of Spring-Loaded Heat Source Supported by Cantilevered RTG Housing

\section{UNDEFORMED}

DEFORMED

(5500 lb Spring Load, 25 Gy Side Load)
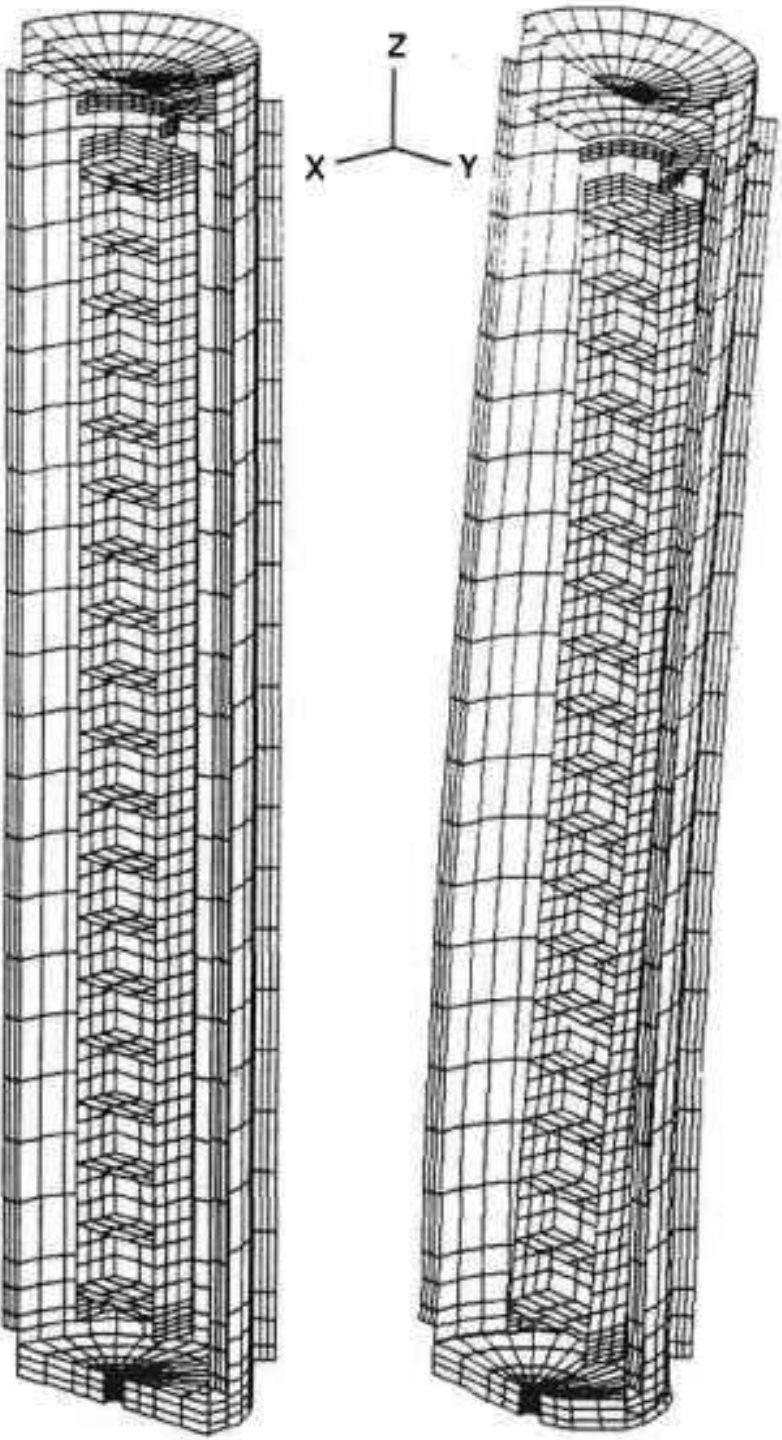
Figure 10 presents the noraal-z stresses and von Mises stresses in the heat source side walls. As can be seen, all of the normal-z stresses are negative. The highest (i,e., least negative) $z$-stress is -1.09 ksi, well within the compressive regime. The computed results suggest that the $5500-16$ preload can probably be reduced to 5000 los without developing any tensile z-stresses. The right half of the figure shows that the maximum von Mises stress, $2.9 \mathrm{ksi}$, is again well within the strength lifmit of the FWPF graphite material. (See Table 1.)

Figure 11 depicts the correspanding von Mises stress distribution in the RTG housing side wall. Two conditions are illustrated: The left

Figure 10. Stresses in Heat Source Aeroshells (ksi)

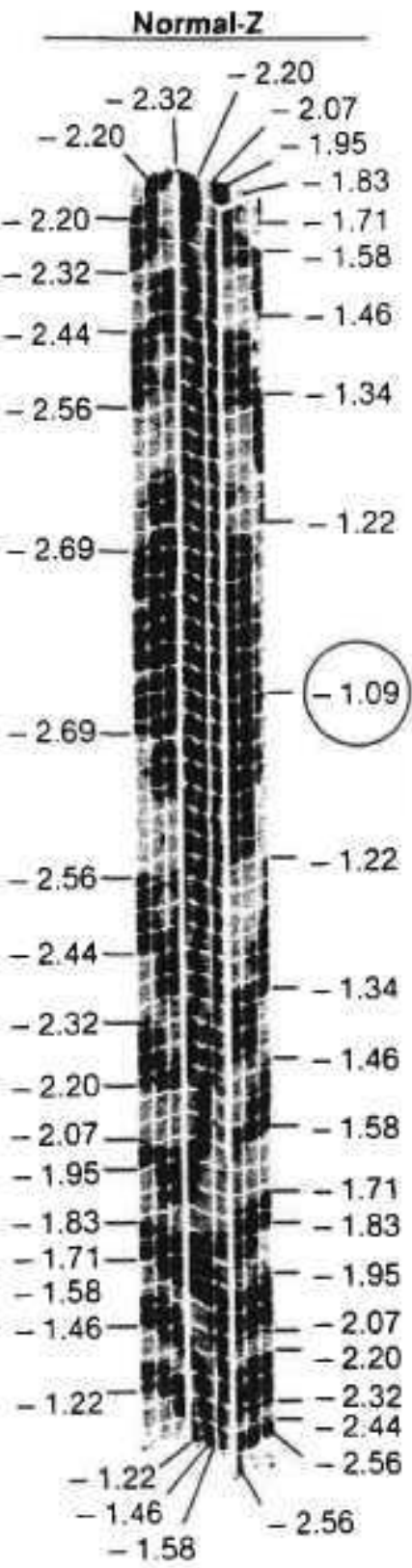

half of the figure shows the short-term launch stresses of the water-cooled RTG housing with a 550010 spring load and a $25 \mathrm{G}$ stde load. The right half of the figure shows the long-term stresses of the radiation-cooled RTG with a 3300 ib spring load and a 15 G side load.

The maximum launch stress, which occurs at the $-y$ side near the base of the RTG, is $-15 \mathrm{ksi}$. This is well below the 31-ksi yield strength of the aluminum alloy $\left(2219\right.$ T85i) at its $171^{\circ} \mathrm{C}$ launch temperature. Similarly, the maximum stress on Mars, $8.5 \mathrm{ksi}$, is oniy $53 \%$ of the alloy's 16 ksi yield strength at its $272^{\circ} \mathrm{C}$ maximum operating temperature.

Figure 11. Von Mises Stresses in Housing Side Wall (ksi)
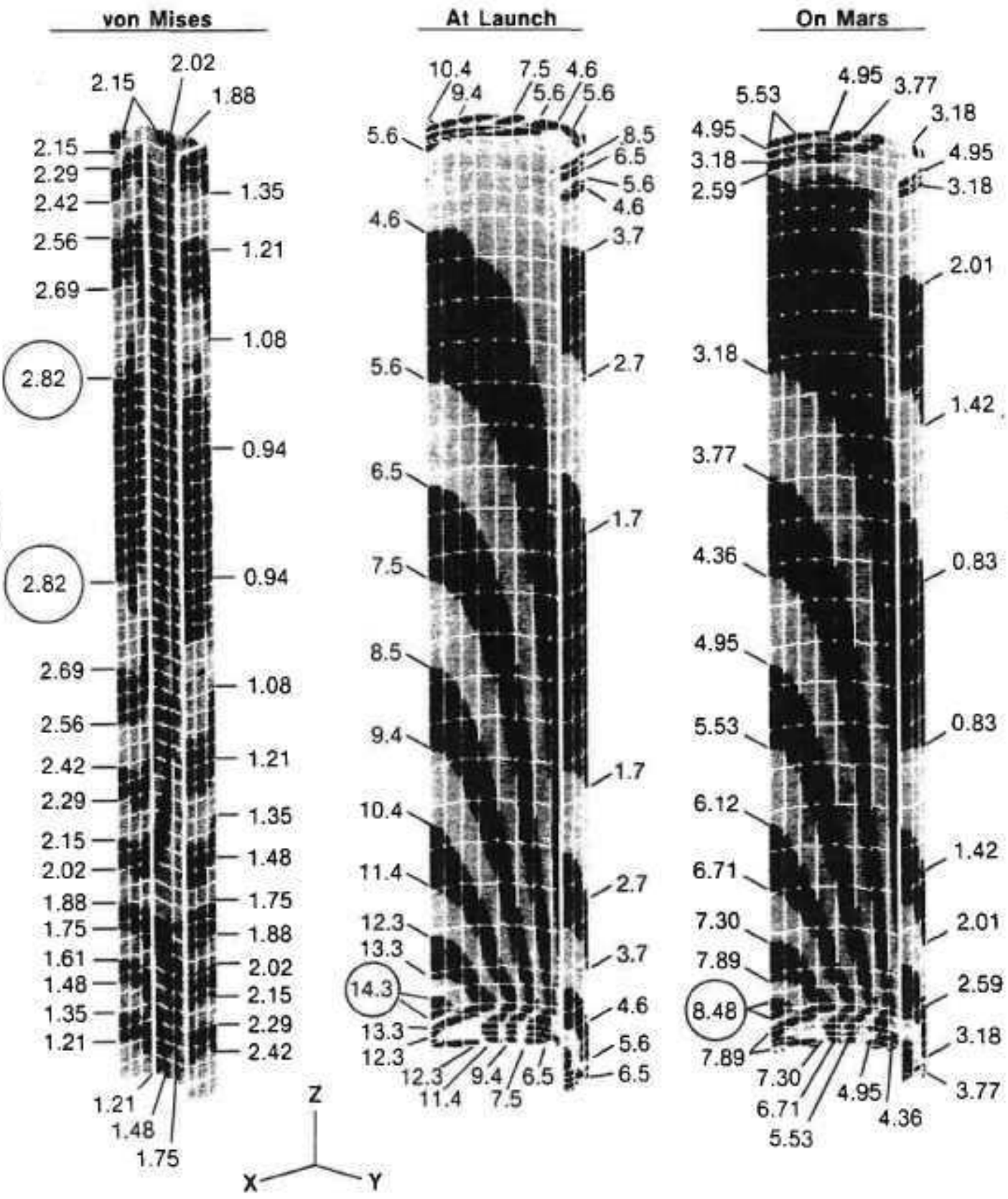
In addition to yield strength, the long-term creep characteristics of the aluminum housing must be considered. The RTG housing, at its thinnest $\left(0.090^{\prime \prime}\right)$ section, has a horizontal cross-section of $2.54 \mathrm{in}^{2}$. Thus, at its maximum operating temperature, the $3300-10$ spring load will produce a steady-state tensile stress of 1.3 ksi. At $272^{\circ} \mathrm{C}$, this tensile stress will produce negligible creep during the four-year mission.

Finally, Figure 12 shows the von Mises stress distributions in the RTG's $0.062^{\text {"-thick }}$ top cap and in its $0.125^{\circ}$-thick baseplate. The top cap is subjected to an external pressure of one atmosphere. Its maximum stress, $-5 \mathrm{ksi}$, is well below the strength of aluminum.

\section{Figure 12. Von Mises Stresses in RTG Top Cover and} Base Plate
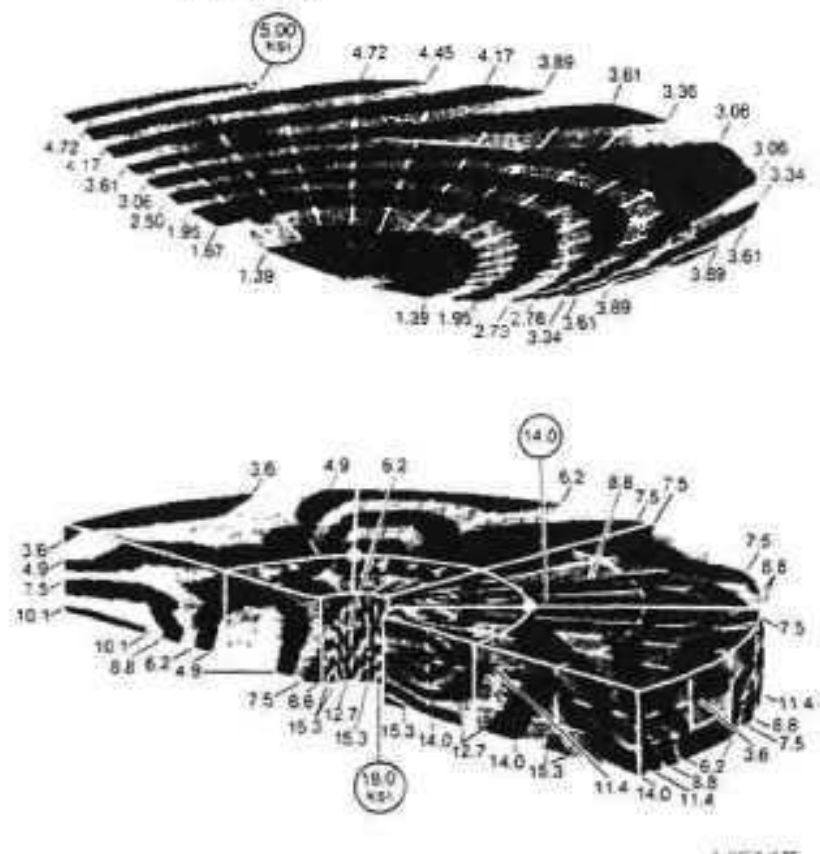

The heavy white lines in the baseplate stress plot show the location of the eight radia? and three circunferential stiffening ribs, which are $0.25^{\prime \prime}$ thick and $1^{\prime \prime}$ high. The two white dots in the figure denote the locations of the heat source support studs. As can be seen, the maxinum stress (18 ksi) occurs at the $\rightarrow y$ side of the inner stiffening ring. A secondary maximum (14 ksi) occurs at the right side of the middle stiffener ring. This location is difectly below one of the two support studs at the $+y$ side of the heat source. The maximum baseplate stress is is $42 \%$ below the 31-ksi yield strength of the aluminum alloy at its $171^{\circ} \mathrm{C}$ launch temperature.

\section{SUMMARY AND CONCLUSIONS}

Detalled NASTRAN analysis of the springloaded heat source supported by the cantilevered RTG housing confirms the feasibility of supporting an 18-module heat source stack without midspan supports, and demonstrates the adequacy of the spring and housing dimensions on which the mass analyses in Reference [2] are based.

\section{REFERENCES}

[1] A. Schock, V. Sankarankandath, and H. Shirbacheh, "Requirements and Designs for Mars Rover RTGs." 24th Intersociety Energy Conversion Englneering Conference, 6-11 August, 1989 ,

[2] A. Schock, I. Or and E. Skrabek, "Thermal and Electrical Analysis of Mars Rover RTGs." 24th Intersoc1ety Energy Conversion Engineering Conference, 6-11 August, 1989.

[3] A. Schock and A. Shostak. "Use of Modular Heat Source Stack in RTGs." Proceedings of the 1979 Intersociety Energy Conversion Engineering Conference, Boston, MA.

[4] A. Hall Jr., A. Holowenko, and H. Laughlin, "Schaun's Out11ne of Theory and Problems of Machine Des1gn," New York: McGrawH111 Book Company, 1980.

\section{ACKNOWLEDGEMENT}

The above work was supported by the U.S. Department of Energy's Office of Special Applications. 
